\title{
Checklist dos "protozoários" de água doce do Estado de São Paulo, Brasil
}

\author{
Mirna Helena Regali-Seleghim ${ }^{1,3}$, Mirna Januária Leal Godinho ${ }^{1}$ \& Takako Matsumura-Tundisi ${ }^{2}$ \\ ${ }^{1}$ Departamento de Ecologia e Biologia Evolutiva,Universidade Federal de São Carlos - UFSCar, \\ Rod. Washington Luiz, Km 235, CEP 13565-905, São Carlos-SP \\ ${ }^{2}$ Instituto Internacional de Ecologia, \\ Rua Bento Carlos, 750, CEP 13560-660, São Carlos - SP, São Carlos, SP, Brasil, e-mail: takako@iie.com.br \\ ${ }^{3}$ Autor para correspondência: Mirna Helena Regali Seleghim, e-mail: pmhrs@iris.ufscar.br
}

REGALI-SELEGHIM, M.H., GODINHO, M.J.L. \& MATSUMURA-TUNDISI, T. Checklist of "protozoans" from São Paulo State, Brazil. Biota Neotrop. 11(1a): http://www.biotaneotropica.org.br/v11n1a/en/abstract?i nventory+bn0141101a2011.

Abstract: Species checklists are important to know the local biodiversity, its ecology and scale its biotechnological and economic exploration and conservation. In this work the protozoan data (ciliates, naked amoebas, tecamoebas, heliozoans and heterotrophic flagellates) from São Paulo State have been listed. From 75 environments analized to this moment, 471 different protozoan taxa were recorded, distributed in 218 genera and 304 species. From the protozoan groups analyzed, the most representative was the ciliate with 160 genera and 219 species. Among the ciliates, two were new records: Neobursaridium gigas Balech, 1941 to Brazil and Loxodes rex Dragesco, 1970 to South America

Keywords: fresh-water protozoans, biodiversity of the State of São Paulo, BIOTA/FAPESP Program.

Number of species: In the world: 8,000, In Brazil: ?, Estimated in São Paulo State: 500.

REGALI-SELEGHIM, M.H., GODINHO, M.J.L. \& MATSUMURA-TUNDISI, T. Checklist dos “protozoários" de água doce do Estado de São Paulo, Brasil. Biota Neotrop. 11(1a): http://www.biotaneotropica.org.br/v11n1a/ pt/abstract?inventory+bn0141101a2011.

Resumo: Listagens de espécies são importantes para o conhecimento da biota de um local, sua ecologia e para podermos dimensionar sua exploração econômica, biotecnológica e conservação. Neste trabalho foram levantados os dados de protozoários (ciliados, amebas nuas, amebas com carapaça, heliozoários e flagelados heterotróficos) de água doce do Estado de São Paulo. De 75 ambientes que foram analisados até o momento, foram registrados um total de 471 diferentes taxa de protozoários distribuídos em 218 generos e 304 espécies. Dos grupos de protozoários avaliados, os mais bem representados foram os ciliados com 160 gêneros e 219 espécies. Dentre os ciliados ocorrerem dois novos registros: Neobursaridium gigas Balech, 1941 para o Brasil e Loxodes rex Dragesco, 1970 para a América do Sul.

Palavras-chave: protozoários de água doce, biota paulista, Programa BIOTA/FAPESP.

Número de espécies: no mundo: 8.000, no Brasil: ?, estimadas no Estado de São Paulo: 500. 


\section{Introdução}

O termo protozoário não tem valor taxonômico, mas ele é frequentemente utilizado quando se quer referir a um organismo unicelular eucarioto heterotrófico que pode ocorrer em diversos habitats onde há água. Os protozoários são encontrados sob a forma livre ou em associação com outros organismos e, neste último caso, são denominados de epibiontes, comensais, simbiontes ou parasitas.

Segundo Finlay \& Esteban (1998), os protozoários de vida livre são caracterizados pela fagotrofia, embora alguns possam se nutrir por algum tipo de habilidade fotossintética. Eles são abundantes em todos os tipos de ambientes aquáticos (plâncton, bentos, subterrâneos e em extremos de salinidade, temperatura, $\mathrm{pH}$ e pressão hidrostática) e solos. Embora considerados de vida livre, frequentemente são encontrados na superfície ou aderidos à rochas, rizosfera de plantas, algas, flocos de cianobactérias, plantas aquáticas, organismos zooplanctônicos, detritos e biofilmes, locais onde o alimento é mais abundante.

Os protozoários de vida livre de água doce são os ciliados, as amebas com e sem carapaça, os heliozoários e os flagelados. Em ambientes aquáticos os protozoários fazem parte de uma rede alimentar complexa, atuando basicamente como elos de ligação entre a produção bacteriana e os produtores secundários (Porter et al. 1985, Berninger et al., 1993) e desempenhando importantes funções tais como: aumento do processo de remineralização (Sherr \& Sherr 1984), controle da densidade bacteriana (Sherr et al., 1987, Sanders et al. 1989, Berninger et al., 1991) e alteração da composição morfológica e taxonômica das comunidades bacterianas pela predação (Jurgens \& Gude 1994, Jurgens et al. 1997). Além disso, várias espécies de ciliados e flagelados são capazes de consumir algas, cianobactérias e outros protozoários, tendo funções semelhantes às dos organismos metazoários (Sherr \& Sherr 1994). Eles podem também aumentar a produção primária em ambientes dominados por protozoários mixotróficos (Pirlot et al. 2005) e influenciar o "pool" de matéria orgânica dissolvida, de vírus e de outras partículas de tamanho viral nos ambientes aquáticos, uma vez que alguns protozoários flagelados podem se alimentar destes componentes (Tranvik et al. 1993, González \& Suttle 1993).

As águas enriquecidas com matéria orgânica podem conter grandes populações de bactérias das quais os protozoários se alimentam. Por isso os protozoários desempenham um importante papel na remoção de bactérias dos efluentes em sistemas de tratamento biológico de águas residuárias e são essenciais nos processos de autopurificação dos mesmos e, provavelmente desempenham funções similares na despoluição de ecossistemas naturais (Curds 1992).

Os protozoários, por possuírem tempo de geração curto e tamanho pequeno, serem encontrados em vários tipos de ambientes, serem sensíveis ao stress e serem coletados com facilidade (Cairns et al., 1993), podem ser utilizados como indicadores no monitoramento de ambientes aquáticos e sistemas de tratamento biológico de esgotos para a avaliação do grau de poluição orgânica (Sladeček 1969). Eles são também utilizados como organismos-teste em experimentos de toxicidade (Twagilimana et al. 1998, Nalecz-Jawecki 2004) devido a sua sensibilidade a alterações ambientais, ao seu curto ciclo de vida e a sua facilidade de cultivo e manutenção. Os protozoários estão também sendo investigados quanto à possibilidade de utilização em controle biológico de florações de algas e de cianobactérias (Sigee et al. 1999) e na produção de metabólitos bioativos (Guella et al. 1994).

\section{Distribuição geográfica dos protozoários de água doce}

Os protozoários são considerados ubíquos, mas a determinação da distribuição geográfica de suas espécies depende da distribuição dos corpos d'água nas diversas áreas do planeta e do número e qualidade das pesquisas nos diferentes ambientes dessas regiões geográficas. A determinação exata consite em um grande desafio, pois os maiores levantamentos faunísticos de protozoários foram feitos na Europa e América do Norte, e o conhecimento nas outras áreas do planeta é muito pequeno. Outras dificuldades para o levantamento desses dados estão ligadas à pouca quantidade de profissionais treinados em taxonomia desses grupos e à incompatibilidades entre metodologias de estudos de caráter taxonômico e ecológico. Segundo Foissner (1994), nos poucos trabalhos ecológicos que incluem os protozoários, sua identificação não foi feita ou o foi de maneira superficial. Por isso, a possibilidade ou não de endemismo para os protozoários de vida livre se tornou objeto de um grande debate (Foissner 1999, Finlay \& Fenchel 1999) que permanece até hoje e que, segundo Mitchell $\&$ Meisterfeld (2005), revela a necessidade de um maior esforço em estudos taxonômicos. Para se tentar resolver a questão, segundo os dois últimos autores, deve-se: 1) melhorar a taxonomia de protozoários de vida livre, combinando características morfológicas com moleculares; 2) intensificar os esforços de amostragem em regiões pouco estudadas; 3) levar em consideração a especificidade das espécies pelos habitats.

Em vista do exposto, há necessidade de avaliação de métodos que permitam uma identificação segura dos protozoários. Tais métodos devem evidenciar caracteres essenciais para diferenciar uma espécie de outra e ter aplicabilidade em estudos ecológicos, necessários para o entendimento das relações tróficas que permitem a sustentabilidade dos ecossitemas, bem como para o conhecimento, manutenção e conservação de espécies que constituem recursos genéticos com aplicações potencialmente úteis.

\section{Taxonomia, classificação e diversidade dos protozoários}

O termo Protozoa, como táxon, foi introduzido por Goldfuss em 1818 para denominar o sub-reino que incluía os protozoários. Como inicialmente incluía alguns organismos como briozoários, posteriormente ele foi modificado por von Siebold em 1845 e passou a incluir apenas organismos unicelulares. Entretanto, sabe-se hoje que esse agrupamento taxonômico é artificial, apresentando organismos de diferentes origens filogenéticas.

Segundo Adl et al. (2007), os estudos filogenéticos baseados em biologia molecular têm afetado os antigos sistemas de classificação dos organismos eucariotos que sofreram, assim, grandes alterações nos últimos 25 anos. Segundo esses autores, um dos grupos mais impactados foi o dos protistas que, segundo Adl et al. (2005), inclui organismos eucarióticos com organização unicelular, colonial, filamentosa ou parenquimatosa, que não possuem diferenciação nos tecidos vegetativos, que pode ocorrer somente na reprodução.

Por questões práticas, na tentativa de reduzir a alta frequência de alterações na classificação dos protistas, Adl e colaboradores em 2005, com o aval da Sociedade Internacional de Protistologia, propuseram um sistema hierárquico de classificação sem as designações formais de ranqueamento, tais como "classe", "sub-classe," "superordem," ou "ordem". Tal sistema de ranqueamento rompeu com aquele tradicionalmente utilizado pelo Código Internacional de Nomenclatura Botânica (para as algas e fungos) e pelo Código Internacional de Nomenclatura Zoológica (para protozoários).

A nova classificação proposta por Adl et al. (2005) dividiu os eucariotos em seis grupos: Amoebozoa, Opisthokonta, Rhizaria, Archaeplastida, Chromalveolata e Excavata. Nesta nova classificação os protozoários ciliados encontram-se no grupo Chromalveolata; as amebas nos grupos Amoebozoa, Rhizaria, Excavata e Chromalveolata; os Heliozoários nos grupos Chromalveolata e Eukaryota; e os flagelados heterotróficos em Rhizaria, Excavata, Chromalveolata, Opistokonta e Eukaryota.

Adl et al. (2007), fez um levantamento sobre o número de espécies conhecidas dos principais grupos de protistas e, à partir desse trabalho, estimamos que o somatório das espécies de protozoários de vida livre (de solo, marinhos e de água doce) chega a aproximadamente 
20.000. Comparando-se este número com as estimativas anteriores de Vickerman (1992), que menciona aproximadamente 36.000 espécies de protozoários conhecidas, a redução pode estar relacionada com: 1) as estimativas mais críticas, avaliando a presença de diversas espécies sinonímeas que fez, por exemplo, com que o número de espécies de Ciliophora passasse de 8.000 para 3.500 ; 2) a não inclusão dos Microsporidia por serem hoje considerados fungos; 3) a não inclusão dos Sporozoa, Myxozoa e Kinetoplastidae pelo fato da maioria de seus representantes não ser de vida livre; 4) o fato de Adl et al. (2007) não apresentarem estimativas de número de espécies para alguns grupos, como as amebas Silicofilosea, os heliozoários do grupo Centrohelida e os flagelados do grupo Collodyctionidae.

Não existe na literatura levantamento recente sobre o número de espécies conhecidas de protozoários encontrados em ambientes de água doce. À partir do número de 20.000 espécies de protozoários de vida livre (estimado de Adl et al. 2007) estimamos também o número aproximado de espécies de protozoários de água doce conhecidos ao descontarmos grupos exclusivamente marinhos e/ou salobros (radiolários e foraminíferos que somam aproximadamente 11.000 espécies); a maioria das espécies de ciliados da ordem Tintinnida (aproximadamente 1.000 espécies) e da classe Karyorelictea (aproximadamente 130 espécies); e espécies isoladas de alguns grupos de ciliados como, por exemplo, Fabrea salina, Myrionecta rubra (antigo Mesodinium rubrum), etc. O valor resultante é pouco menor, mas próximo de 8.000 espécies de protozoários de água doce conhecidos. O número exato de espécies de ciliados e flagelados exclusivamente marinhos, de água doce ou marinhos facultativos é difícil de ser avaliado, pois a maioria das espécies possui ecologia, fisiologia e distribuição geográfica ainda pouco conhecida e existem espécies novas sendo descritas. Portanto, não existe pesquisa suficiente para afirmarmos com segurança a natureza de todas as espécies para podermos calcular o valor exato das espécies de água doce. Temos que considerar também que esse valor estimado de 8.000 está incluindo espécies típicas de solo, entretanto sabe-se que estas são frequentemente encontradas em ambientes de água doce pela sua proximidade e por serem introduzidas pelo ar e pela chuva.

\section{Metodologia}

Neste estudo foram levantados os dados do protozooplâncton de água doce de 75 ambientes no Estado de São Paulo (Tabela 1). A Tabela 1 mostra os ambientes analisados, inseridos em suas Unidades de Gerenciamento dos Recursos Hídricos (UGRHI) do estado, com suas coordenadas geográficas e as referências bibliográficas das fontes dos dados de protozoários para cada ambiente em questão. Os protozoários considerados foram os ciliados, as amebas nuas, as amebas com carapaça, os heliozoários e os flagelados heterotróficos. Os ciliados foram classificados segundo Lynn (2008), e as amebas (com e sem carapaça), heliozoários e flagelados heterotróficos foram classificados segundo o Systema Naturae 2.000 (Brands 1989-2005).

\section{Resultados e Discussão}

\section{Comentários sobre a lista de espécies do Estado de São Paulo}

As Tabelas 2, 3, 4, 5 e 6 referem-se as listas de espécies encontradas nos corpos de água do Estado de São Paulo separadas respectivamente em Ciliados, Amebas com carapaça (Tecamebas), Amebas sem carapaça (nuas), Heliozoarios e Flagelados. Dos 75 ambientes estudados no Estado de São Paulo, 8 já faziam parte do primeiro levantamento feito por Godinho e Regali-Seleghim em 1999, nos quais haviam sido encontradas 69 espécies dentre 148 gêneros de protozoários. No atual levantamento, feito pouco mais de 10 anos após o primeiro, além desses 8 ambientes já estudados, 56 novos corpos de água foram analisados no âmbito do Programa BIOTA/FAPESP. A Tabela 1 e a Figura 1 mostram que os 75 ambientes estudados estão distribuídos em 12 das 22 UGRHI do Estado de São Paulo e que existem importantes bacias que não foram ainda estudadas. As principais lacunas ficaram na região sudoeste do Estado; algumas unidades litorâneas na bacia da Baixada Santista, Litoral Norte e do Paraíba do Sul; e as bacias do Baixo Pardo/Grande e Tietê Batalha. A Figura 1 mostra as 22 UGRHI do Estado de São Paulo onde, em média, 10 corpos de água para cada UGRHI foram amostrados, porém nem todas UGRHIs puderam ser estudadas no âmbito do Programa BIOTA/Fapesp, restringindo-se às seguintes Unidades: Mantiqueira, Pardo, Alto Tietê, Ribeira do Iguape/Litoral Sul e Mogi-Guaçú. As análises cumulativas de novos taxa de ciliados à cada corpo d'água analisado por UGRHI mostraram que o número de taxa não se estabilizava com o aumento do número de amostragens, o que levou a concluir que existe a necessidade de maior investimento em estudos taxonômicos nessas UGRHI (Godinho et al. 2003). A Figura 2 mostra o acréscimo de táxons novos à cada unidade analisada. Tal análise revela que, embora alguns taxa sejam comuns e frequentes em todas as unidades, existe um incremento de novos taxa à cada unidade analisada, indicando a importância do prosseguimento dos estudos nas outras unidades do Estado.

As outras unidades que não foram estudadas pelo Programa BIOTA/FAPESP, e que foram também destacadas no mapa, tiveram apenas 1 a 3 ambientes estudados. Baseado nas conclusões obtidas por Godinho et al. (2003), apresentadas acima, podemos concluir que a amostragem dessas unidades também foi insuficiente. Dentre as unidades que não foram estudadas pelo Programa BIOTA/FAPESP, uma que se destacou das outras foi a UGRHI Tietê/Jacaré que teve 4 ambientes estudados, sendo que alguns deles foram estudados intensivamente por diferentes pesquisadores e em diferentes ocasiões, como é o caso do Reservatório do Monjolinho e a Represa do Lobo. Esses ambientes com maior quantidade de amostras analisadas apresentaram grande diversidade de espécies. Para o Reservatório do Monjolinho foi registrado um total de 250 taxa de protozoários e para a Represa do Lobo 131 taxa. Por outro lado, Mansano (2008) analisou o reservatório de Ilha Solteira em um estudo de dois anos e observou apenas 53 taxa. Tais valores são proporcionalmente pequenos quando comparados com os do reservatório do Monjolinho, do Lobo, e de alguns ambientes que tiveram apenas 1 coleta dentro do Programa BIOTA/FAPESP como a Lagoa do Diogo, que apresentou 47 taxa e a Represa Euclides da Cunha que apresentou 44 taxa. Por outro lado, os ambientes analisados apenas $1 \mathrm{vez}$ no Programa BIOTA/FAPESP tinham, em média, entre 17 e 20 taxa, sendo que o valor mínimo encontrado por ambiente foi de 5 e o máximo de 47. Isso mostra que o número de taxa por ambiente é influenciado pelo número de coletas, bem como pelas características intrínsecas de cada local. Segundo Finlay \& Esteban (1998) o valor normalmente esperado em 1 única amostra de ambiente aquático é de cerca de 20 espécies de protozoários e, para ambientes com aproximadamente 1 hectare, amostrados por vários anos, é de cerca de 250 espécies. No caso dos ambientes amostrados 1 só vez, nossos valores médios são muito similares aos apresentados por Finlay \& Esteban, entretanto, os valores máximos são bem maiores (mais do que o dobro) e os mínimos chegam a um quarto de sua estimativa, o que reforça a importância das características intrínsecas de cada ambiente (físicas, químicas e biológicas) que determinará o número real encontrado. Quanto ao número encontrado no Reservatório do Monjolinho este é o mesmo do estimado por Finlay \& Esteban para ambientes mais intensivamente amostrados. 
Regali-Seleghim, M.H. et al.

Tabela 1. Relação dos corpos de água nas UGRHIs do Estado de São Paulo, onde os protozoários foram analisados.

Table 1. Water bodies of São Paulo State Water Resources Management Units (UGRHI) were protozoans were analyzed.

\begin{tabular}{|c|c|c|c|c|c|}
\hline UGRHI/Bacia & Corpos d'água & Município & $\begin{array}{l}\text { Códigos dos } \\
\text { corpos d'água }\end{array}$ & Coordenadas & Referências \\
\hline \multirow[t]{17}{*}{1 Mantiqueira } & Represa Fojo & Campos do Jordão & 1 & $\begin{array}{l}22^{\circ} 42^{\prime} 91 " \text { 'S e } \\
45^{\circ} 32 \text { ' } 09 \text { ' } \mathrm{W}\end{array}$ & $\begin{array}{c}\text { Godinho \& Regali- } \\
\text { Seleghim }(2000,2001)\end{array}$ \\
\hline & L. Marginal do Fojo & Campos do Jordão & 2 & $\begin{array}{l}22^{\circ} 42^{\prime} 94^{\prime \prime} \mathrm{S} \mathrm{e} \\
45^{\circ} 32^{\prime} 08^{\prime \prime} \mathrm{W}\end{array}$ & $\begin{array}{c}\text { Godinho \& Regali- } \\
\text { Seleghim }(2000,2001)\end{array}$ \\
\hline & Lagoa dos Lambaris & Campos do Jordão & 3 & $\begin{array}{l}22^{\circ} 41^{\prime} 39^{\prime \prime} \mathrm{S} \mathrm{e} \\
45^{\circ} 28,96 " \mathrm{~W}\end{array}$ & $\begin{array}{c}\text { Godinho \& Regali- } \\
\text { Seleghim }(2000,2001)\end{array}$ \\
\hline & Lagoa Ninfóides & Campos do Jordão & 4 & $\begin{array}{l}22^{\circ} 41^{\prime} 44^{\prime \prime} \mathrm{S} \mathrm{e} \\
45^{\circ} 29^{\prime} 14^{\prime \prime} \mathrm{W}\end{array}$ & $\begin{array}{c}\text { Godinho \& Regali- } \\
\text { Seleghim }(2000,2001)\end{array}$ \\
\hline & Horto Lagoa 1 & Campos do Jordão & 5 & $\begin{array}{l}22^{\circ} 44^{\prime} 22^{\prime \prime} \mathrm{S} \mathrm{e} \\
45^{\circ} 35^{\prime} 29^{\prime \prime} \mathrm{W}\end{array}$ & $\begin{array}{c}\text { Godinho \& Regali- } \\
\text { Seleghim }(2000,2001)\end{array}$ \\
\hline & Horto Lagoa 2 & Campos do Jordão & 6 & $\begin{array}{l}22^{\circ} 44^{\prime} 22^{\prime \prime} \mathrm{S} \mathrm{e} \\
45^{\circ} 35^{\prime} 29^{\prime \prime} \mathrm{W}\end{array}$ & $\begin{array}{c}\text { Godinho \& Regali- } \\
\text { Seleghim }(2000,2001)\end{array}$ \\
\hline & Horto Lagoa 3 & Campos do Jordão & 7 & $\begin{array}{l}22^{\circ} 44^{\prime} 22^{\prime \prime} \mathrm{S} \mathrm{e} \\
45^{\circ} 35^{\prime} 29^{\prime \prime} \mathrm{W}\end{array}$ & $\begin{array}{c}\text { Godinho \& Regali- } \\
\text { Seleghim }(2000,2001)\end{array}$ \\
\hline & Horto Lagoa 4 & Campos do Jordão & 8 & $\begin{array}{l}22^{\circ} 44^{\prime} 22 ", \mathrm{~S} \mathrm{e} \\
45^{\circ} 35^{\prime} 29^{\prime \prime} \mathrm{W}\end{array}$ & $\begin{array}{c}\text { Godinho \& Regali- } \\
\text { Seleghim }(2000,2001)\end{array}$ \\
\hline & Horto Lagoa 5 & Campos do Jordão & 9 & $\begin{array}{l}22^{\circ} 44^{\prime} 22^{\prime \prime} \mathrm{S} \mathrm{e} \\
45^{\circ} 35^{\prime} 29^{\prime \prime} \mathrm{W}\end{array}$ & $\begin{array}{c}\text { Godinho \& Regali- } \\
\text { Seleghim }(2000,2001)\end{array}$ \\
\hline & Represa Sta. Isabel & Campos do Jordão & 10 & $\begin{array}{l}22^{\circ} 43^{\prime} 58^{\prime \prime} \mathrm{S} \mathrm{e} \\
45^{\circ} 27^{\prime} 01^{\prime \prime} \mathrm{W}\end{array}$ & $\begin{array}{c}\text { Godinho \& Regali- } \\
\text { Seleghim }(2000,2001)\end{array}$ \\
\hline & Riacho das Trutas & Campos do Jordão & 11 & $\begin{array}{l}22^{\circ} 43^{\prime} 34^{\prime \prime} \mathrm{S} \mathrm{e} \\
45^{\circ} 27^{\prime} 09^{\prime \prime} \mathrm{W}\end{array}$ & $\begin{array}{c}\text { Godinho \& Regali- } \\
\text { Seleghim }(2000,2001)\end{array}$ \\
\hline & Lagoa Tundra & Campos do Jordão & 12 & $\begin{array}{l}22^{\circ} 43^{\prime} 30^{\prime \prime} \mathrm{S} \mathrm{e} \\
45^{\circ} 27^{\prime} 13^{\prime \prime} \mathrm{W}\end{array}$ & $\begin{array}{c}\text { Godinho \& Regali- } \\
\text { Seleghim }(2000,2001)\end{array}$ \\
\hline & Lavrinhas Lagoa 1 & Campos do Jordão & 13 & $\begin{array}{l}22^{\circ} 42^{\prime} 13^{\prime \prime} \mathrm{S} \mathrm{e} \\
45^{\circ} 25^{\prime} 20^{\prime \prime} \mathrm{W}\end{array}$ & $\begin{array}{c}\text { Godinho \& Regali- } \\
\text { Seleghim }(2000,2001)\end{array}$ \\
\hline & Lavrinhas Lagoa 2 & Campos do Jordão & 14 & $\begin{array}{l}22^{\circ} 41^{\prime} 84^{\prime \prime} \mathrm{S} \mathrm{e} \\
45^{\circ} 25^{\prime} 15^{\prime \prime} \mathrm{W}\end{array}$ & $\begin{array}{c}\text { Godinho \& Regali- } \\
\text { Seleghim }(2000,2001)\end{array}$ \\
\hline & Represa Itapeva & Campos do Jordão & 15 & $\begin{array}{l}22^{\circ} 46^{\prime} 19^{\prime \prime} \mathrm{S} \mathrm{e} \\
45^{\circ} 31^{\prime} 79^{\prime \prime} \mathrm{W}\end{array}$ & $\begin{array}{c}\text { Godinho \& Regali- } \\
\text { Seleghim }(2000,2001)\end{array}$ \\
\hline & Hípica Lago 2 & Campos do Jordão & 16 & $\begin{array}{l}22^{\circ} 43^{\prime} 34^{\prime \prime} \mathrm{S} \mathrm{e} \\
45^{\circ} 33^{\prime} 07^{\prime \prime} \mathrm{W}\end{array}$ & $\begin{array}{c}\text { Godinho \& Regali- } \\
\text { Seleghim }(2000,2001)\end{array}$ \\
\hline & Lagoa Vila Inglesa & Campos do Jordão & 17 & $\begin{array}{l}22^{\circ} 44^{\prime} 47^{\prime \prime} \mathrm{S} \mathrm{e} \\
45^{\circ} 34^{\prime} 10^{\prime \prime} \mathrm{W}\end{array}$ & $\begin{array}{c}\text { Godinho \& Regali- } \\
\text { Seleghim }(2000,2001)\end{array}$ \\
\hline \multirow[t]{8}{*}{4 Pardo } & Represa Graminha & Caconde & 18 & $21^{\circ} 34^{\prime} 80^{\prime \prime} \mathrm{S}$ e $47^{\circ} 37^{\prime} 16^{\prime \prime} \mathrm{W}$ & Godinho et al. (2002) \\
\hline & Represa Itaiquara & Divinolândia & 19 & $21^{\circ} 35^{\prime} 08^{\prime \prime}$ S e $46^{\circ} 44^{\prime} 86^{\prime \prime} \mathrm{W}$ & Godinho et al. (2002) \\
\hline & Fazenda Graminha & $\begin{array}{l}\text { São José do } \\
\text { Rio Pardo }\end{array}$ & 20 & $\begin{array}{l}21^{\circ} 32^{\prime} 92^{\prime \prime} \mathrm{S} \mathrm{e} \\
46^{\circ} 49^{\prime} 60^{\prime \prime} \mathrm{W}\end{array}$ & Godinho et al. (2002) \\
\hline & R. Euclides da Cunha & $\begin{array}{l}\text { São José do } \\
\text { Rio Pardo }\end{array}$ & 21 & $\begin{array}{l}21^{\circ} 36^{\prime} 05^{\prime \prime} \mathrm{S} \mathrm{e} \\
46^{\circ} 56^{\prime} 90^{\prime \prime} \mathrm{W}\end{array}$ & Godinho et al. (2002) \\
\hline & $\begin{array}{l}\text { Represa } \\
\text { Limoeiro }\end{array}$ & $\begin{array}{l}\text { São José do } \\
\text { Rio Pardo }\end{array}$ & 22 & & Godinho et al. (2002) \\
\hline & $\begin{array}{l}\text { R. Fazenda Sta. } \\
\text { Helena }\end{array}$ & $\begin{array}{l}\text { São José do } \\
\text { Rio Pardo }\end{array}$ & 23 & $\begin{array}{l}21^{\circ} 32^{\prime} 06^{\prime \prime} \mathrm{S} \mathrm{e} \\
46^{\circ} 50^{\prime} 49^{\prime \prime} \mathrm{W}\end{array}$ & Godinho et al. (2002) \\
\hline & Lago Paço Municipal & Jaboticabal & 24 & $\begin{array}{l}23^{\circ} 05^{\prime} 01^{\prime \prime} \mathrm{S} \mathrm{e} \\
48^{\circ} 33^{\prime} 53^{\prime \prime} \mathrm{W}\end{array}$ & Godinho et al. (2002) \\
\hline & $\begin{array}{l}\text { Viveiros de } \\
\text { piscicultura }\end{array}$ & Jaboticabal & 25 & $\begin{array}{l}21^{\circ} 15^{\prime} 22^{\prime \prime} \mathrm{S} \mathrm{e} \\
48^{\circ} 18^{\prime} 58^{\prime \prime} \mathrm{W}\end{array}$ & $\begin{array}{l}\text { Sipaúba-Tavares et al. } \\
\text { (1995) } \\
\text { Durigan et al. (1992) } \\
\text { Oliveira et al. (1992) }\end{array}$ \\
\hline
\end{tabular}


Tabela 1. Continuação...

\begin{tabular}{|c|c|c|c|c|c|}
\hline UGRHI/Bacia & Corpos d'água & Município & $\begin{array}{c}\text { Códigos dos } \\
\text { corpos d'água }\end{array}$ & Coordenadas & Referências \\
\hline & Lago Monte Alegre & Ribeirão Preto & 26 & $\begin{array}{l}21^{\circ} 11^{\prime} \mathrm{S} \mathrm{e} \\
47^{\circ} 43^{\prime} \mathrm{W}\end{array}$ & $\begin{array}{l}\text { Gomes \& Godinho } \\
\text { (2003) }\end{array}$ \\
\hline \multirow{10}{*}{$\begin{array}{c}5 \text { Piracicaba/ } \\
\text { Capivari/Jundiaí } \\
6 \text { Alto Tietê }\end{array}$} & $\begin{array}{c}\text { Reservatório Salto } \\
\text { Grande }\end{array}$ & Americana & 27 & $\begin{array}{l}22^{\circ} 44^{\prime} \mathrm{S} \mathrm{e} \\
47^{\circ} 19^{\prime} \mathrm{W}\end{array}$ & Arantes Jr. et al. (2004) \\
\hline & Reservatório Billings & $\begin{array}{c}\text { São Bernardo do } \\
\text { Campo }\end{array}$ & 28 & $\begin{array}{l}23^{\circ} 45^{\prime} 49^{\prime \prime}, \mathrm{S} \mathrm{e} \\
46^{\circ} 30^{\prime} 96^{\prime \prime} \mathrm{W}\end{array}$ & $\begin{array}{l}\text { Barbieri \& Godinho- } \\
\text { Orlandi (1989a); } \\
\text { Koyama (2001); } \\
\text { Godinho et al. (2002); }\end{array}$ \\
\hline & R.de Águas Claras & Mairiporã & 29 & $\begin{array}{l}23^{\circ} 23^{\prime} 91^{\prime \prime} \mathrm{S} \mathrm{e} \\
46^{\circ} 39^{\prime} 52^{\prime \prime} \mathrm{W}\end{array}$ & $\begin{array}{c}\text { Koyama (2001); } \\
\text { Godinho et al. (2002) }\end{array}$ \\
\hline & Represa Ponte Nova & Salesópolis & 30 & $\begin{array}{l}23^{\circ} 35^{\prime} 83^{\prime \prime} \mathrm{S} \mathrm{e} \\
45^{\circ} 58^{\prime} 78^{\prime \prime} \mathrm{W}\end{array}$ & $\begin{array}{c}\text { Koyama (2001); } \\
\text { Godinho et al. (2002) }\end{array}$ \\
\hline & Represa Paiva Castro & Mairiporã & 31 & $\begin{array}{l}23^{\circ} 19^{\prime} 95^{\prime \prime} \mathrm{S} \mathrm{e} \\
46^{\circ} 39^{\prime} 24^{\prime \prime} \mathrm{W}\end{array}$ & $\begin{array}{c}\text { Koyama (2001); } \\
\text { Godinho et al. (2002) }\end{array}$ \\
\hline & Represa Taiaçupeba & $\begin{array}{l}\text { Mogi das } \\
\text { Cruzes }\end{array}$ & 32 & $\begin{array}{l}23^{\circ} 34^{\prime}, 80^{\prime \prime} \mathrm{S} \mathrm{e} \\
46^{\circ} 16^{\prime} 92^{\prime \prime} \mathrm{W}\end{array}$ & $\begin{array}{c}\text { Koyama (2001); } \\
\text { Godinho et al. (2002) }\end{array}$ \\
\hline & $\begin{array}{l}\text { R. Cachoeira das } \\
\text { Graças }\end{array}$ & Cotia & 33 & $\begin{array}{l}23^{\circ} 39^{\prime} 22^{\prime \prime} \mathrm{S} \mathrm{e} \\
46^{\circ} 58^{\prime} 62^{\prime} \mathrm{W}\end{array}$ & $\begin{array}{c}\text { Koyama (2001); } \\
\text { Godinho et al. (2002) }\end{array}$ \\
\hline & Represa Pedro Beicht & Cotia & 34 & $\begin{array}{l}23^{\circ} 43^{\prime} 52^{\prime \prime} \mathrm{S} \mathrm{e} \\
46^{\circ} 57^{\prime} 63^{\prime \prime} \mathrm{W}\end{array}$ & $\begin{array}{c}\text { Koyama (2001); } \\
\text { Godinho et al. (2002) }\end{array}$ \\
\hline & P. Ecológico Lago 1 & Guarulhos & 35 & $\begin{array}{l}23^{\circ} 29^{\prime} 19^{\prime \prime} \mathrm{S} \mathrm{e} \\
46^{\circ} 30^{\prime} 80^{\prime \prime} \mathrm{W}\end{array}$ & $\begin{array}{c}\text { Koyama (2001) } \\
\text { Godinho et al. (2002); } \\
\text { Lahr, } 2006\end{array}$ \\
\hline & P. Ecológico Lago 2 & Guarulhos & 36 & $\begin{array}{l}23^{\circ} 29^{\prime} 71^{\prime \prime}, \mathrm{S} \mathrm{e} \\
46^{\circ} 31^{\prime} 80^{\prime \prime} \mathrm{W}\end{array}$ & $\begin{array}{c}\text { Koyama (2001); } \\
\text { Godinho et al. (2002) }\end{array}$ \\
\hline $\begin{array}{l}8 \text { Sapucaí/ } \\
\text { Grande }\end{array}$ & $\begin{array}{l}\text { Reservatório de } \\
\text { Igarapava }\end{array}$ & Igarapava & 37 & $\begin{array}{l}20^{\circ} 02^{\prime} 18^{\prime \prime}, \mathrm{S} \mathrm{e} \\
47^{\circ} 51^{\prime} 00^{\prime \prime} \mathrm{W}\end{array}$ & Rolla et al. (1992) \\
\hline \multirow[t]{13}{*}{9 Mogi-Guaçu } & Represa São Geraldo & Sertãozinho & 38 & $\begin{array}{l}22^{\circ} 19^{\prime} 43^{\prime \prime} \mathrm{S} \mathrm{e} \\
46^{\circ} 45^{\prime} 44^{\prime \prime} \mathrm{W}\end{array}$ & Bagatini (2006) \\
\hline & Represa David & $\begin{array}{l}\text { Sta. Cruz das } \\
\text { Palmeiras }\end{array}$ & 39 & $\begin{array}{l}22^{\circ} 19^{\prime} 43^{\prime \prime} \mathrm{S} \mathrm{e} \\
46^{\circ} 45^{\prime} 46^{\prime \prime} \mathrm{W}\end{array}$ & Godinho et al. (2003) \\
\hline & Lago Fazenda Aurora & $\begin{array}{l}\text { Sta. Cruz das } \\
\text { Palmeiras }\end{array}$ & 40 & $\begin{array}{l}20^{\circ} 59^{\prime} 82^{\prime \prime}, \mathrm{S} \mathrm{e} \\
47^{\circ} 58^{\prime} 94^{\prime \prime} \mathrm{W}\end{array}$ & Godinho et al. (2003) \\
\hline & Lagoa do Barro Preto & Guatapará & 41 & $\begin{array}{l}21^{\circ} 29^{\prime} 63^{\prime \prime}, \mathrm{S} \mathrm{e} \\
48^{\circ} 01^{\prime} 98^{\prime \prime} \mathrm{W}\end{array}$ & Bagatini (2006) \\
\hline & Lagoa das Cabras & Rincão & 42 & $21^{\circ} 29^{\prime} 14^{\prime \prime} \mathrm{S}$ e $48^{\circ} 03^{\prime} 72^{\prime \prime} \mathrm{W}$ & Bagatini (2006) \\
\hline & Lagoa da Prainha & Pitangueiras & 43 & $19^{\circ} 59^{\prime} 50^{\prime \prime} \mathrm{S}$ e $49^{\circ} 23^{\prime} 90^{\prime \prime} \mathrm{W}$ & Godinho et al. (2003) \\
\hline & $\begin{array}{c}\text { R. Elektro - } \\
\text { Cachoeira Emas }\end{array}$ & Pirassununga & 44 & $\begin{array}{l}21^{\circ} 58^{\prime} 98^{\prime \prime}, \mathrm{S} \mathrm{e} \\
47^{\circ} 52^{\prime} 68^{\prime \prime} \mathrm{W}\end{array}$ & Godinho et al. (2003) \\
\hline & Lago Municipal & Araras & 45 & $\begin{array}{l}22^{\circ} 21^{\prime} 68^{\prime \prime}, \mathrm{S} \mathrm{e} \\
47^{\circ} 23^{\prime} 00^{\prime \prime} \mathrm{W}\end{array}$ & Bagatini (2006) \\
\hline & Lago Ivo Carotini & Águas de Lindóia & 46 & $22^{\circ} 27^{\prime} 95^{\prime \prime} \mathrm{S}$ e $46^{\circ} 37^{\prime} 66^{\prime \prime} \mathrm{W}$ & Godinho et al. (2003) \\
\hline & $\begin{array}{c}\text { Lagoa Praça Basílio } \\
\text { Seschini }\end{array}$ & Águas da Prata & 47 & $\begin{array}{l}21^{\circ} 56^{\prime} 06^{\prime \prime} \mathrm{S} \mathrm{e} \\
46^{\circ} 42^{\prime} 94^{\prime \prime} \mathrm{W}\end{array}$ & Godinho et al. (2003) \\
\hline & Lago Urbano & $\begin{array}{l}\text { Santa Cruz da } \\
\text { Conceição }\end{array}$ & 48 & $\begin{array}{l}19^{\circ} 59^{\prime} 50^{\prime \prime} \mathrm{S} \mathrm{e} \\
49^{\circ} 23^{\prime} 90^{\prime \prime} \mathrm{W}\end{array}$ & Godinho et al. (2003) \\
\hline & Lagoa do Infernão & Luis Antônio & 49 & $\begin{array}{l}21^{\circ} 22^{\prime} 37^{\prime \prime} \mathrm{S} \mathrm{e} \\
47^{\circ} 46^{\prime} 51^{\prime \prime} \mathrm{W}\end{array}$ & $\begin{array}{l}\text { Bossolan \& Godinho } \\
\qquad(2000)\end{array}$ \\
\hline & Lagoa do Diogo & Luis Antônio & 50 & $21^{\circ} 22^{\prime} 37^{\prime \prime} \mathrm{S}$ e $47^{\circ} 46^{\prime} 51^{\prime} \mathrm{W}$ & Bagatini (2006) \\
\hline 10 Tietê/Sorocaba & $\begin{array}{l}\text { Canal do Inferno- (B. } \\
\text { Edgard de Souza) }\end{array}$ & $\begin{array}{l}\text { Santana do } \\
\text { Parnaíba }\end{array}$ & 51 & $\begin{array}{l}23^{\circ} 27^{\prime} 14^{\prime \prime} \mathrm{S} \mathrm{e} \\
46^{\circ} 54^{\prime} 37^{\prime \prime} \mathrm{W}\end{array}$ & Prowasek (1910) \\
\hline
\end{tabular}


Tabela 1. Continuação...

\begin{tabular}{|c|c|c|c|c|c|}
\hline UGRHI/Bacia & Corpos d'água & Município & $\begin{array}{c}\text { Códigos dos } \\
\text { corpos d'água }\end{array}$ & Coordenadas & Referências \\
\hline \multirow{13}{*}{$\begin{array}{l}11 \text { Ribeira do } \\
\text { Iguape/Litoral Sul }\end{array}$} & R. Barra Bonita & Barra Bonita & 52 & $22^{\circ} 29^{\prime} \mathrm{S}$ e $48^{\circ} 34^{\prime} \mathrm{W}$ & Araújo (2009) \\
\hline & $\begin{array}{l}\text { L. Marginal Ribeira } \\
\text { do Iguape }\end{array}$ & Iporanga & 53 & $\begin{array}{l}24^{\circ} 34^{\prime} 11^{\prime \prime} \mathrm{S} \mathrm{e} \\
48^{\circ} 33^{\prime} 15^{\prime \prime} \mathrm{W}\end{array}$ & $\begin{array}{c}\text { Mai (2002); } \\
\text { Godinho et al. (2003) }\end{array}$ \\
\hline & Represa Iporanga & Iporanga & 54 & $\begin{array}{l}24^{\circ} 06^{\prime} 08^{\prime \prime} \mathrm{S} \text { e } \\
47^{\circ} 43^{\prime} 48^{\prime \prime} \mathrm{W}\end{array}$ & $\begin{array}{c}\text { Mai (2002); } \\
\text { Godinho et al. (2003) }\end{array}$ \\
\hline & $\begin{array}{l}\text { Lago Congregação } \\
\text { Cristã }\end{array}$ & Eldorado & 55 & $\begin{array}{l}24^{\circ} 33^{\prime} 01^{\prime \prime} \mathrm{S} \mathrm{e} \\
48^{\circ} 08^{\prime} 04^{\prime \prime} \mathrm{W}\end{array}$ & $\begin{array}{c}\text { Mai (2002); } \\
\text { Godinho et al. (2003) }\end{array}$ \\
\hline & $\begin{array}{l}\text { Represa de } \\
\text { Juquiazinho }\end{array}$ & Tapiraí & 56 & $\begin{array}{l}23^{\circ} 56^{\prime} 00^{\prime \prime} \mathrm{S} \mathrm{e} \\
47^{\circ} 30^{\prime} 25^{\prime \prime} \mathrm{W}\end{array}$ & $\begin{array}{c}\text { Mai (2002); } \\
\text { Godinho et al. (2003) }\end{array}$ \\
\hline & Represa Japonês & Tapiraí & 57 & $\begin{array}{l}23^{\circ} 56^{\prime} 49^{\prime \prime} \mathrm{S} \mathrm{e} \\
47^{\circ} 30^{\prime} 08^{\prime \prime} \mathrm{W}\end{array}$ & $\begin{array}{c}\text { Mai (2002); } \\
\text { Godinho et al. (2003) }\end{array}$ \\
\hline & Represa Porto Raso & Tapiraí & 58 & $\begin{array}{l}24^{\circ} 03^{\prime} 30^{\prime \prime} \mathrm{S} \mathrm{e} \\
47^{\circ} 24^{\prime} 35^{\prime \prime} \mathrm{W}\end{array}$ & $\begin{array}{c}\text { Mai (2002); } \\
\text { Godinho et al. (2003) }\end{array}$ \\
\hline & Represa Barra & Tapiraí & 59 & $\begin{array}{l}24^{\circ} 00^{\prime} 00^{\prime \prime} \mathrm{S} \mathrm{e} \\
47^{\circ} 20^{\prime} 37^{\prime \prime} \mathrm{W}\end{array}$ & $\begin{array}{c}\text { Mai (2002); } \\
\text { Godinho et al. (2003) }\end{array}$ \\
\hline & Represa Serraria & Juquiá & 60 & $\begin{array}{l}24^{\circ} 08^{\prime} 43^{\prime \prime} \mathrm{S} \mathrm{e} \\
47^{\circ} 32^{\prime} 27^{\prime \prime} \mathrm{W}\end{array}$ & $\begin{array}{c}\text { Mai (2002); } \\
\text { Godinho et al. (2003) }\end{array}$ \\
\hline & Represa Alecrim & Juquiá & 61 & $\begin{array}{l}24^{\circ} 04^{\prime} 46^{\prime \prime} \mathrm{S} \text { e } \\
47^{\circ} 28^{\prime} 34^{\prime \prime} \mathrm{W}\end{array}$ & $\begin{array}{c}\text { Mai (2002); } \\
\text { Godinho et al. (2003) }\end{array}$ \\
\hline & $\begin{array}{l}\text { R. Cachoeira do } \\
\text { França }\end{array}$ & Ibiúna & 62 & $\begin{array}{l}23^{\circ} 56^{\prime} 04^{\prime \prime} \mathrm{S} \mathrm{e} \\
47^{\circ} 11^{\prime} 20^{\prime \prime} \mathrm{W}\end{array}$ & $\begin{array}{c}\text { Mai (2002); } \\
\text { Godinho et al. (2003) }\end{array}$ \\
\hline & Represa Fumaça & Ibiúna & 63 & $\begin{array}{l}24^{\circ} 00^{\prime} 16^{\prime \prime} \mathrm{S} \mathrm{e} \\
47^{\circ} 15^{\prime} 40^{\prime \prime} \mathrm{W}\end{array}$ & $\begin{array}{c}\text { Mai (2002); } \\
\text { Godinho et al. (2003) }\end{array}$ \\
\hline & Represa Jurupará & Piedade & 64 & $\begin{array}{l}23^{\circ} 57^{\prime} 19^{\prime \prime} \mathrm{S} \mathrm{e} \\
47^{\circ} 23^{\prime} 58^{\prime \prime} \mathrm{W}\end{array}$ & $\begin{array}{c}\text { Mai (2002); } \\
\text { Godinho et al. (2003) }\end{array}$ \\
\hline \multirow[t]{4}{*}{13 Tietê/Jacaré } & $\begin{array}{c}\text { Represa do Lobo/ } \\
\text { Broa }\end{array}$ & Brotas/ Itirapina & 65 & $22^{\circ} 15^{\prime} \mathrm{S}$ e $47^{\circ} 49^{\prime} \mathrm{W}$ & $\begin{array}{c}\text { Barbieri \& Godinho- } \\
\text { Orlandi (1989b); Koyama } \\
\text { (2001); Mansano (2010); } \\
\text { Neumann-Leitão et al. } \\
\text { (1991) }\end{array}$ \\
\hline & $\begin{array}{l}\text { Represa do } \\
\text { Monjolinho }\end{array}$ & São Carlos & 66 & $22^{\circ} 01^{\prime} \mathrm{S}$ e $45^{\circ} 53^{\prime} \mathrm{W}$ & $\begin{array}{c}\text { Regali-Seleghim (1992, } \\
\text { 2001, observações } \\
\text { pessoais); Hisatugo } \\
(2009)\end{array}$ \\
\hline & Rio Monjolinho & São Carlos & 67 & $21^{\circ} 57^{\prime} \mathrm{S}$ e $47^{\circ} 50^{\prime} \mathrm{W}$ & Chinalia (1996) \\
\hline & Rio Jacaré-Guaçú & São Carlos & 68 & $21^{\circ} 57^{\prime} \mathrm{S}$ e $47^{\circ} 50^{\prime} \mathrm{W}$ & Chinalia (1996) \\
\hline \multirow[t]{2}{*}{$\begin{array}{c}14 \text { Alto } \\
\text { Paranapanema }\end{array}$} & $\begin{array}{l}\text { Reservatório de } \\
\text { Jurumirim }\end{array}$ & & 69 & $23^{\circ} 30^{\prime} \mathrm{S}$ e $48^{\circ} 40^{\prime} \mathrm{S}$ & $\begin{array}{l}\text { Casanova (2005); } \\
\text { Sartori et al. (2009); } \\
\text { Nogueira (2001) }\end{array}$ \\
\hline & $\begin{array}{l}\text { Lago Coqueiral } \\
\text { (Marginal R. } \\
\text { Jurumirim) }\end{array}$ & & 70 & & Nadai \& Henry (2009) \\
\hline \multirow[t]{2}{*}{15 Turvo/Grande } & Córrego do Talhado & $\begin{array}{c}\text { Talhado-S. J. Rio } \\
\text { Preto }\end{array}$ & 71 & $20^{\circ} 42^{\prime} \mathrm{S} 49^{\circ} 18^{\prime} \mathrm{W}$ & Fulone et al. (2005) \\
\hline & $\begin{array}{l}\text { Córrego do } \\
\text { Talhadinho }\end{array}$ & $\begin{array}{c}\text { Talhado-S. J. Rio } \\
\text { Preto }\end{array}$ & 72 & $20^{\circ} 42^{\prime} \mathrm{S} 49^{\circ} 18^{\prime} \mathrm{W}$ & Fulone et al. (2005) \\
\hline \multirow[t]{3}{*}{19 Baixo Tietê } & $\begin{array}{c}\text { Reservatório Ilha } \\
\text { Solteira }\end{array}$ & Ilha Solteira & 73 & $\begin{array}{l}20^{\circ} 24^{\prime} 38^{\prime \prime} \mathrm{S} \mathrm{e} \\
51^{\circ} 17^{\prime} 59^{\prime \prime} \mathrm{W}\end{array}$ & Mansano (2008) \\
\hline & $\begin{array}{c}\text { Salto de Itapura } \\
\text { (Reservatório Jupiá) }\end{array}$ & Barbosa & 74 & $20^{\circ} 39^{\prime} 09^{\prime \prime} \mathrm{S} 51^{\circ} 30^{\prime} 43^{\prime \prime} \mathrm{W}$ ) & Prowasek (1910) \\
\hline & $\begin{array}{c}\text { Salto Avanhandava } \\
\text { (Res.Nova } \\
\text { Avanhandava) }\end{array}$ & Santana de Parnaíba & 75 & $\begin{array}{l}21^{\circ} 16^{\prime} 00^{\prime \prime} \mathrm{S} \mathrm{e} \\
49^{\circ} 56^{\prime} 57^{\prime \prime} \mathrm{W}\end{array}$ & Prowasek (1910) \\
\hline
\end{tabular}


Protozoários de água doce do Estado de São Paulo

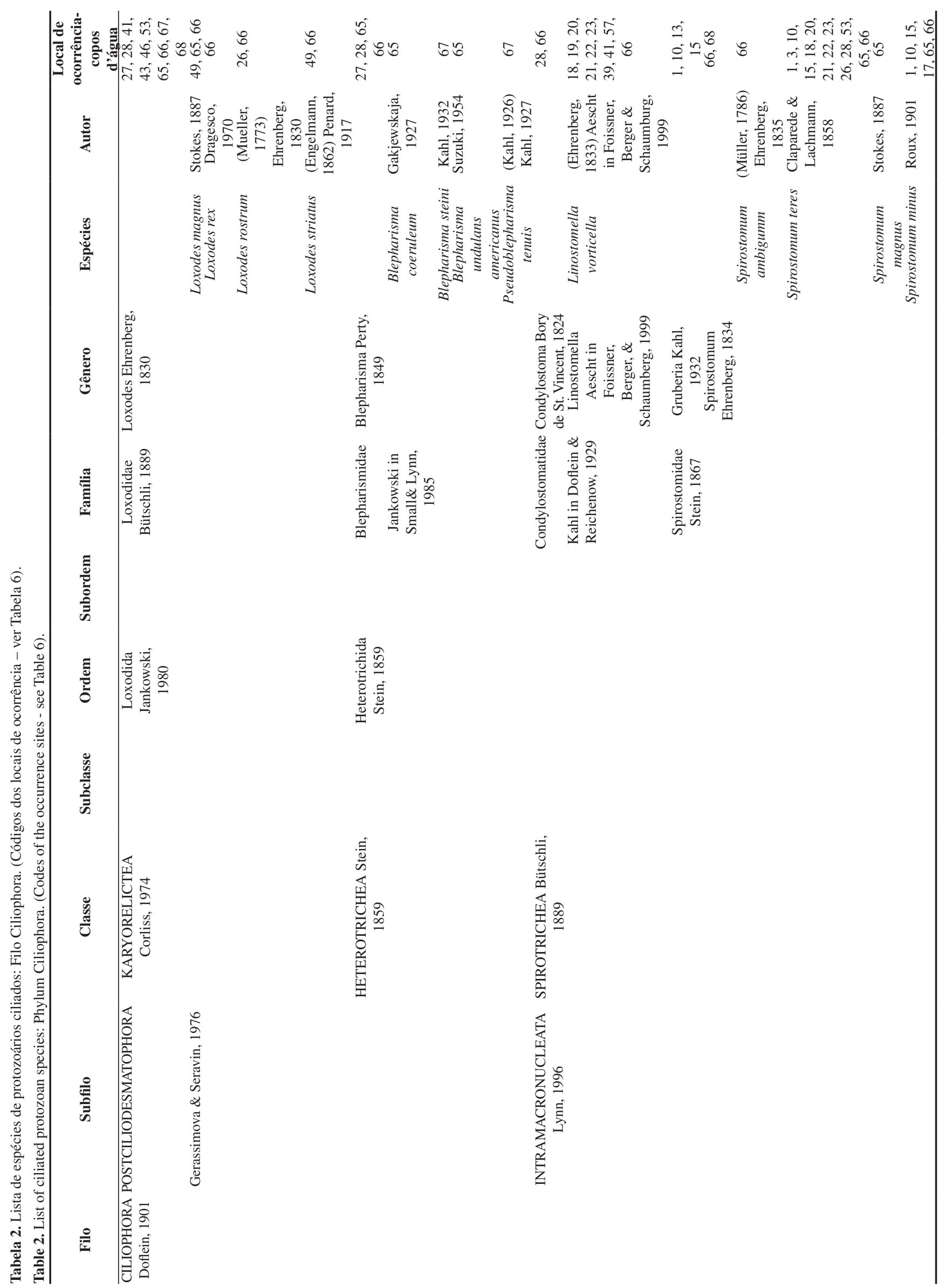


Regali-Seleghim, M.H. et al.

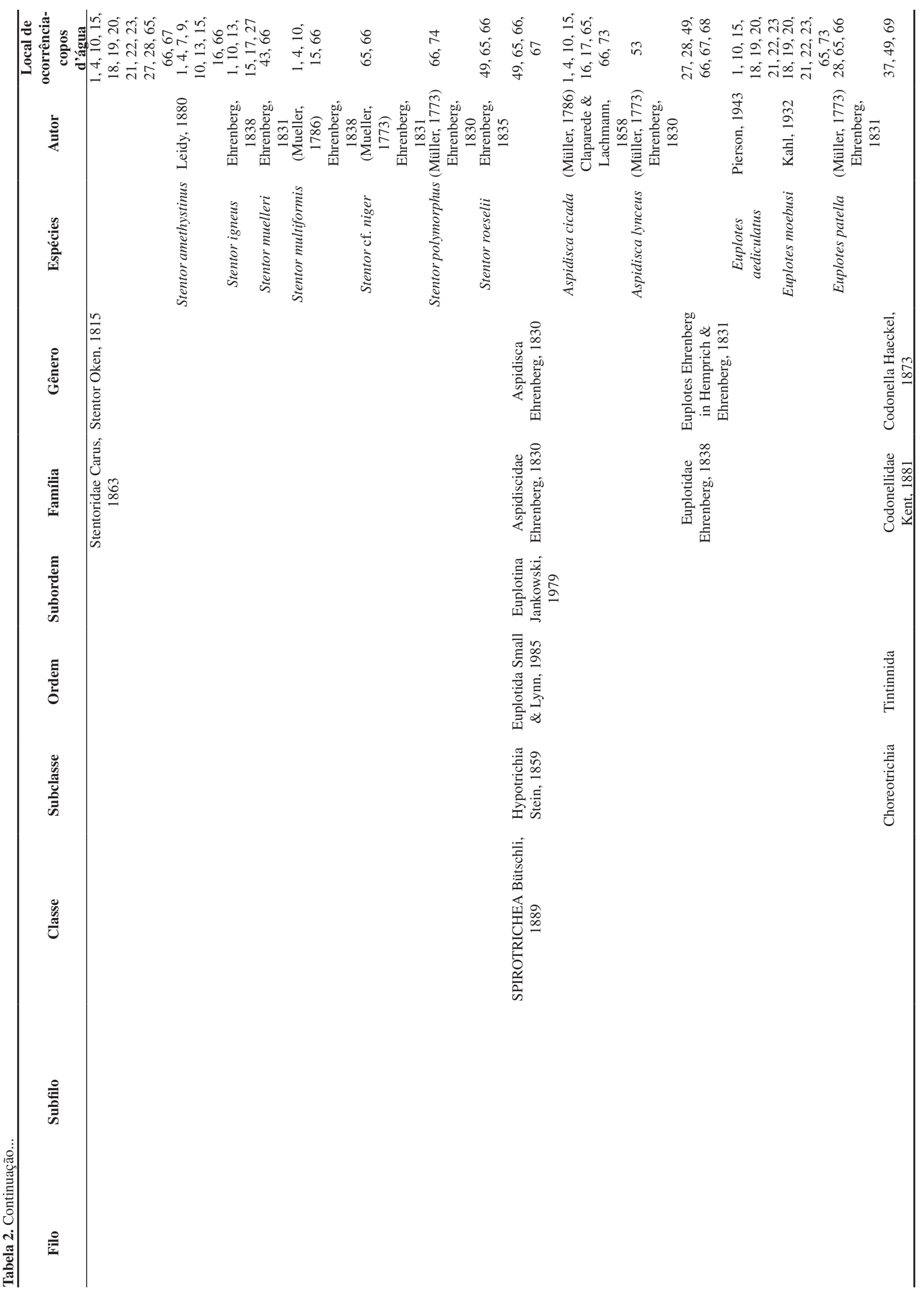




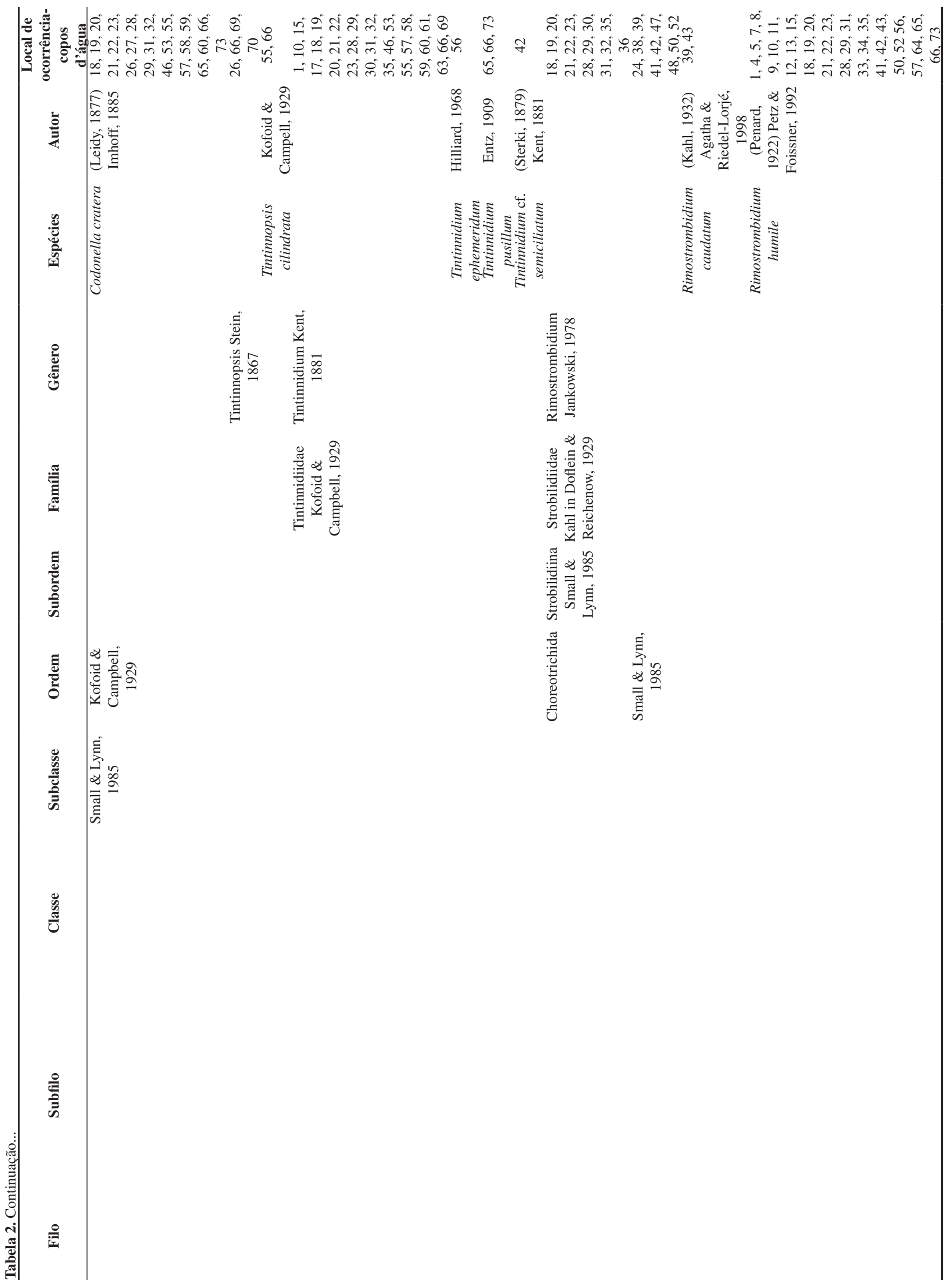


Regali-Seleghim, M.H. et al.

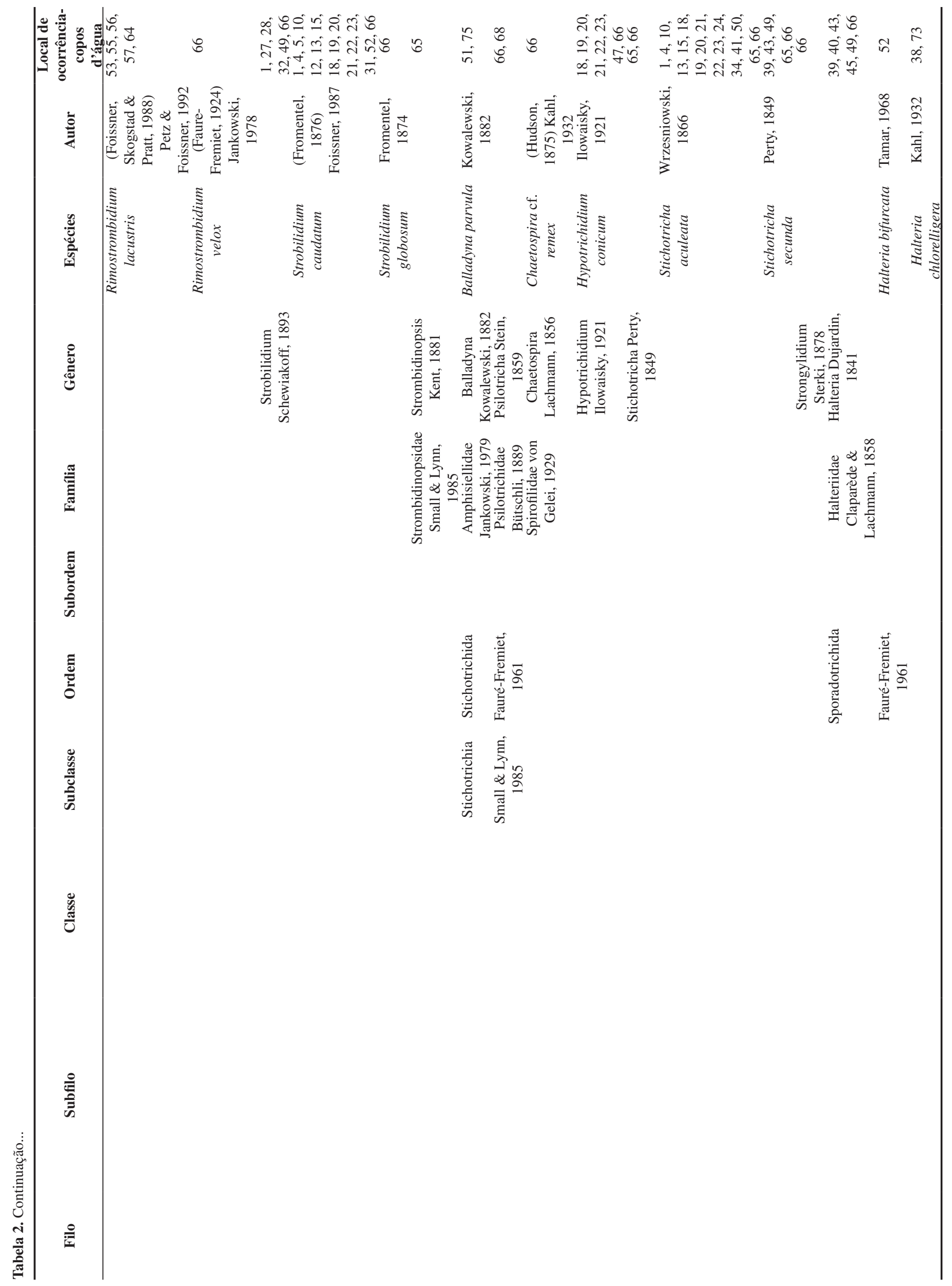


Protozoários de água doce do Estado de São Paulo

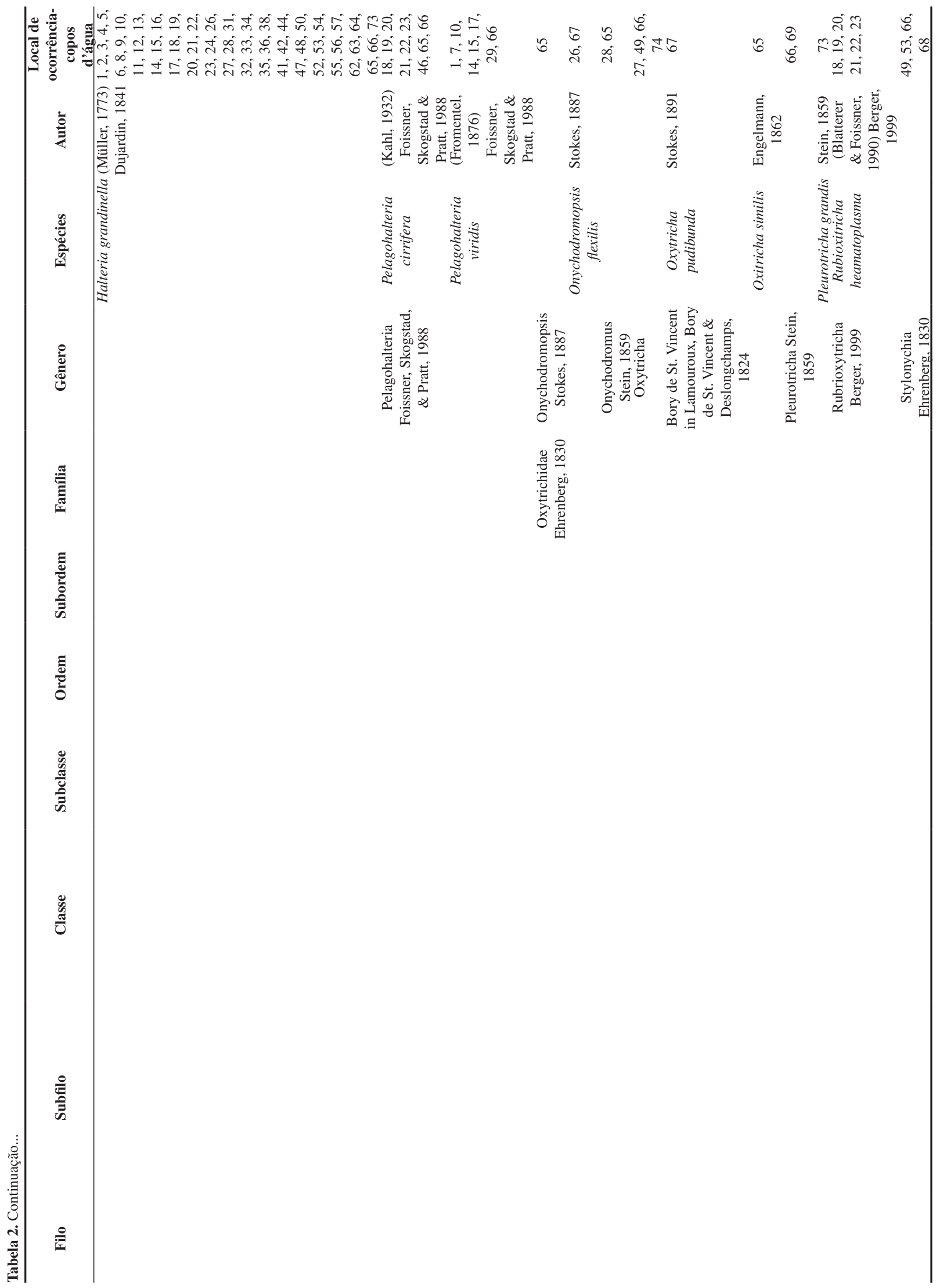


Regali-Seleghim, M.H. et al.

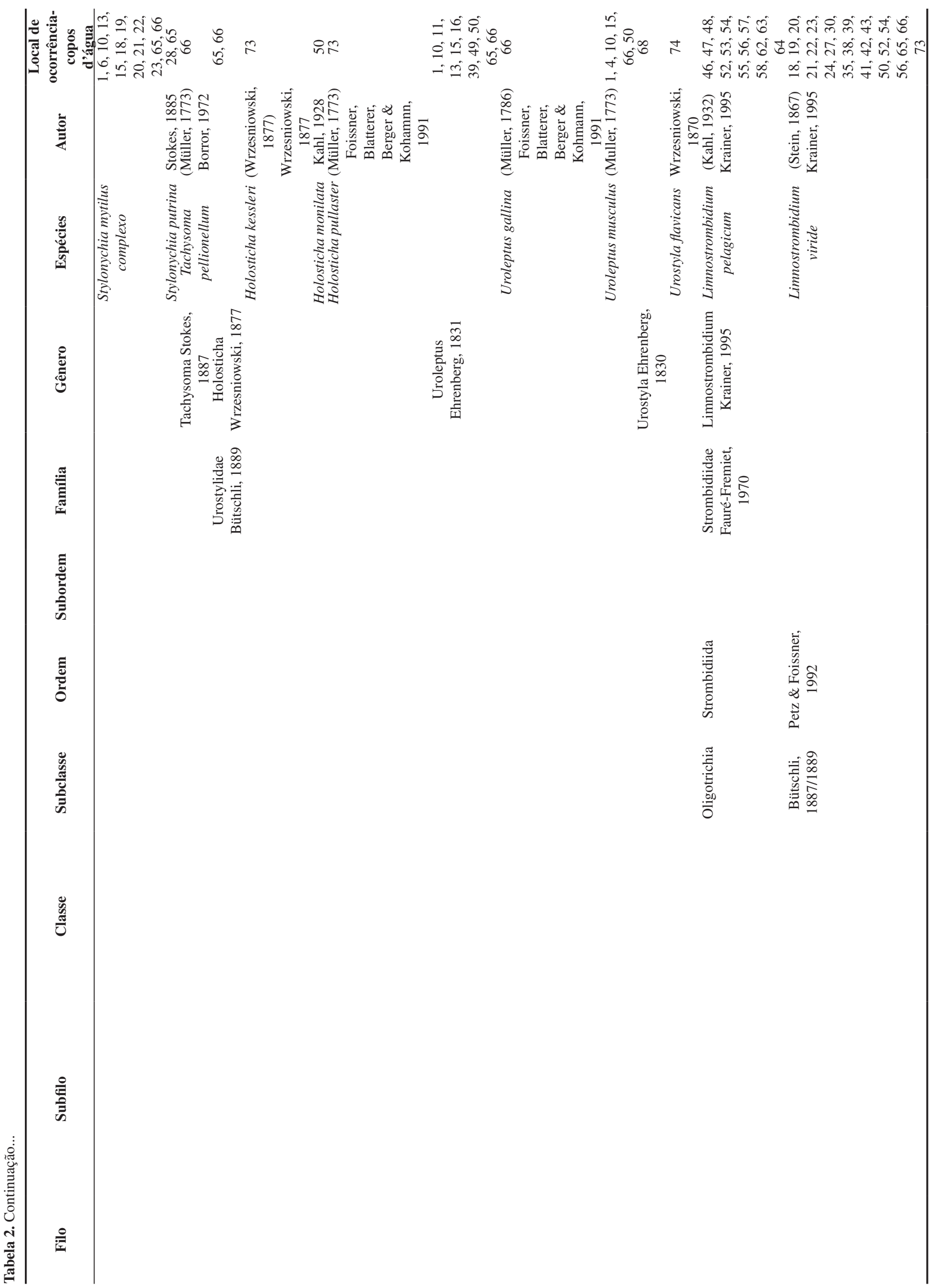




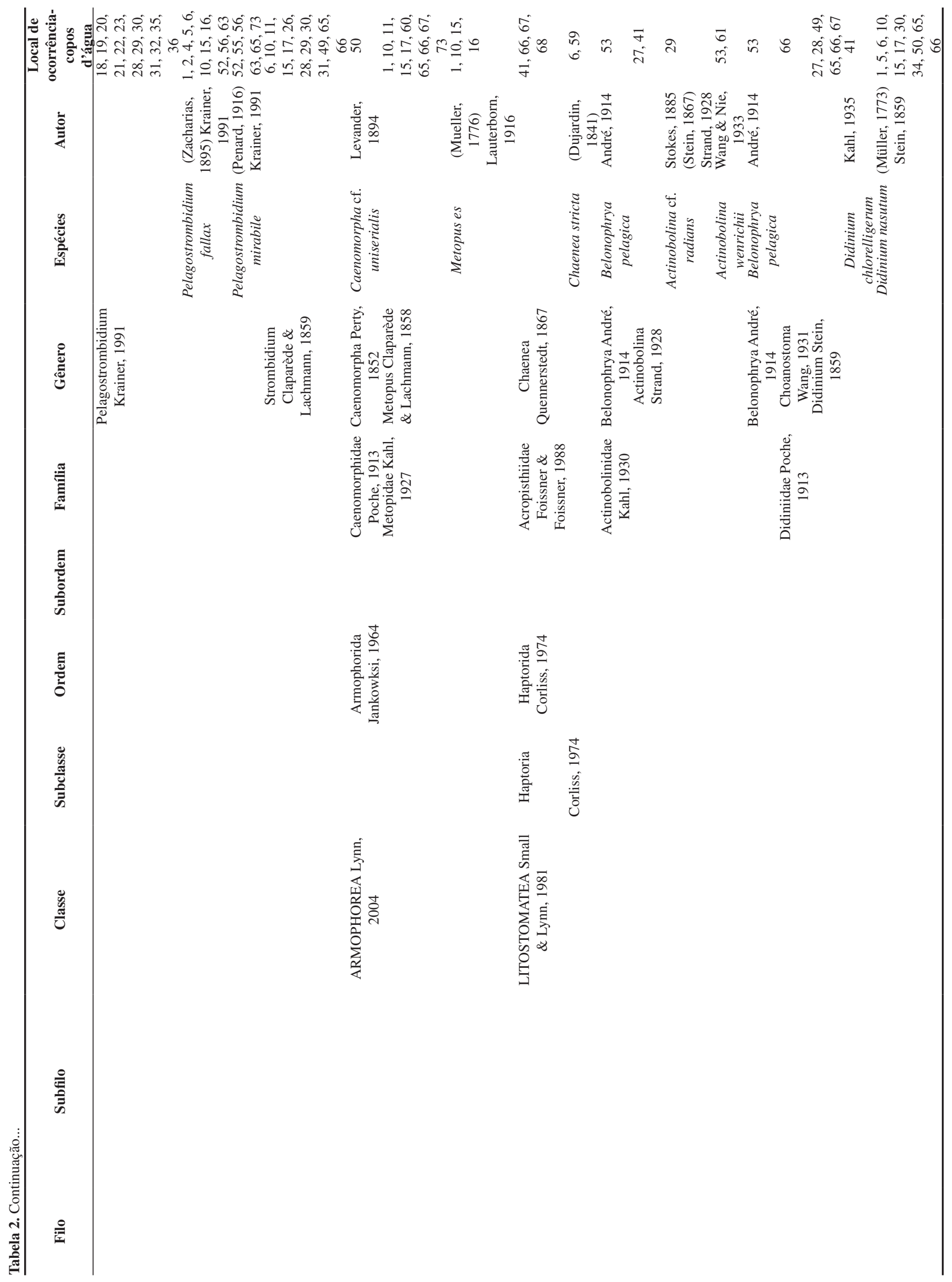


Regali-Seleghim, M.H. et al.

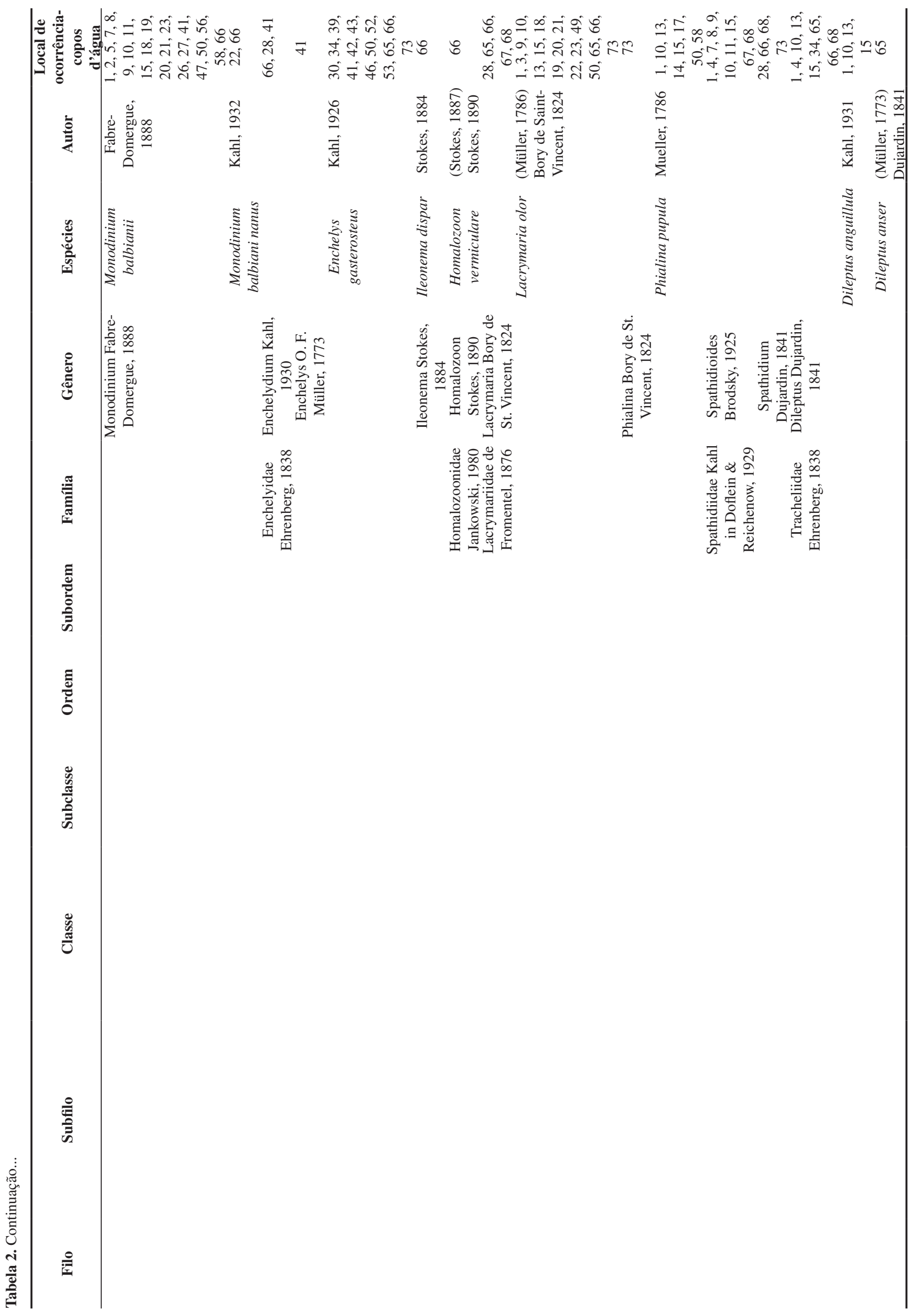


Protozoários de água doce do Estado de São Paulo

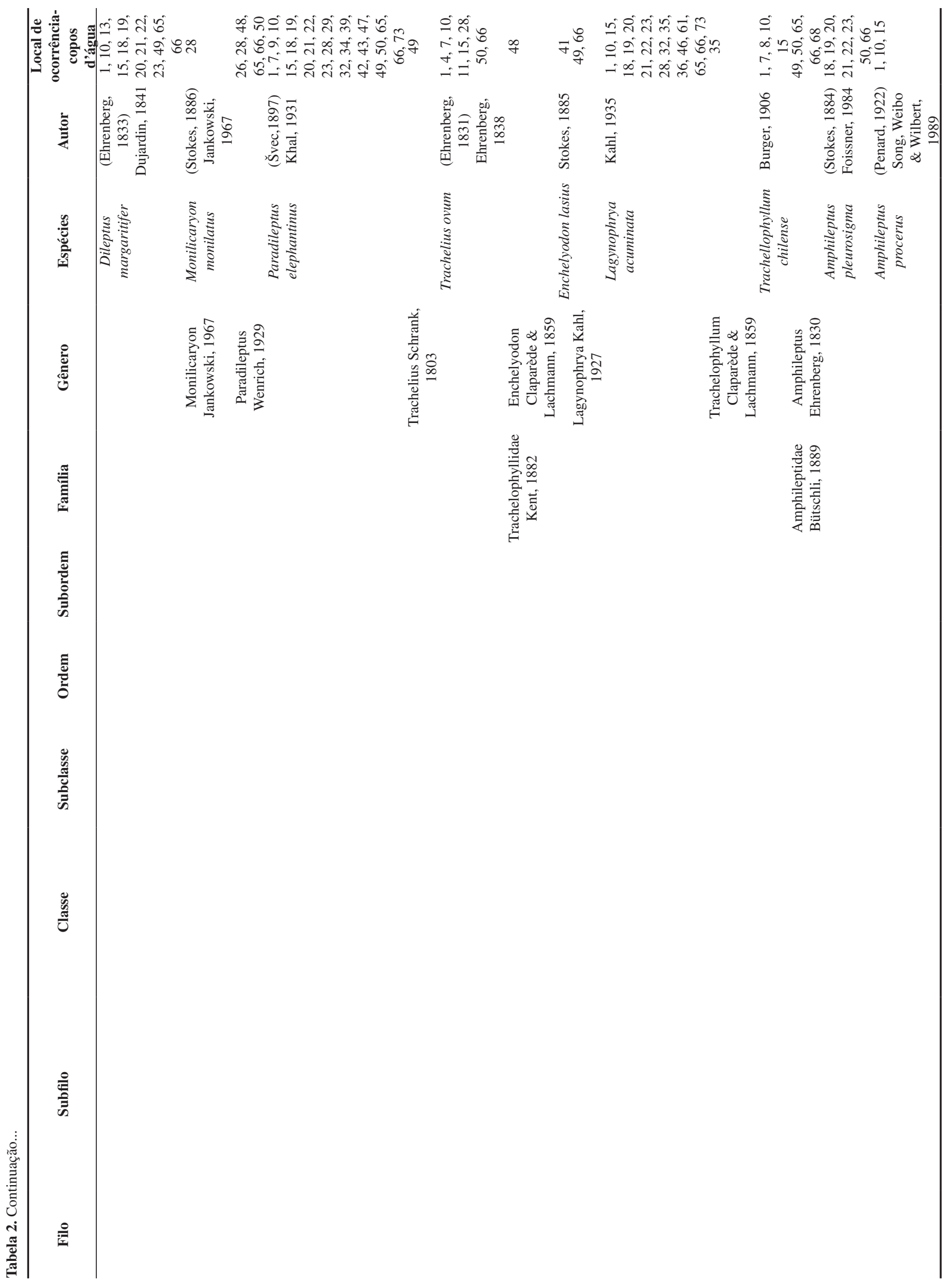


Regali-Seleghim, M.H. et al.

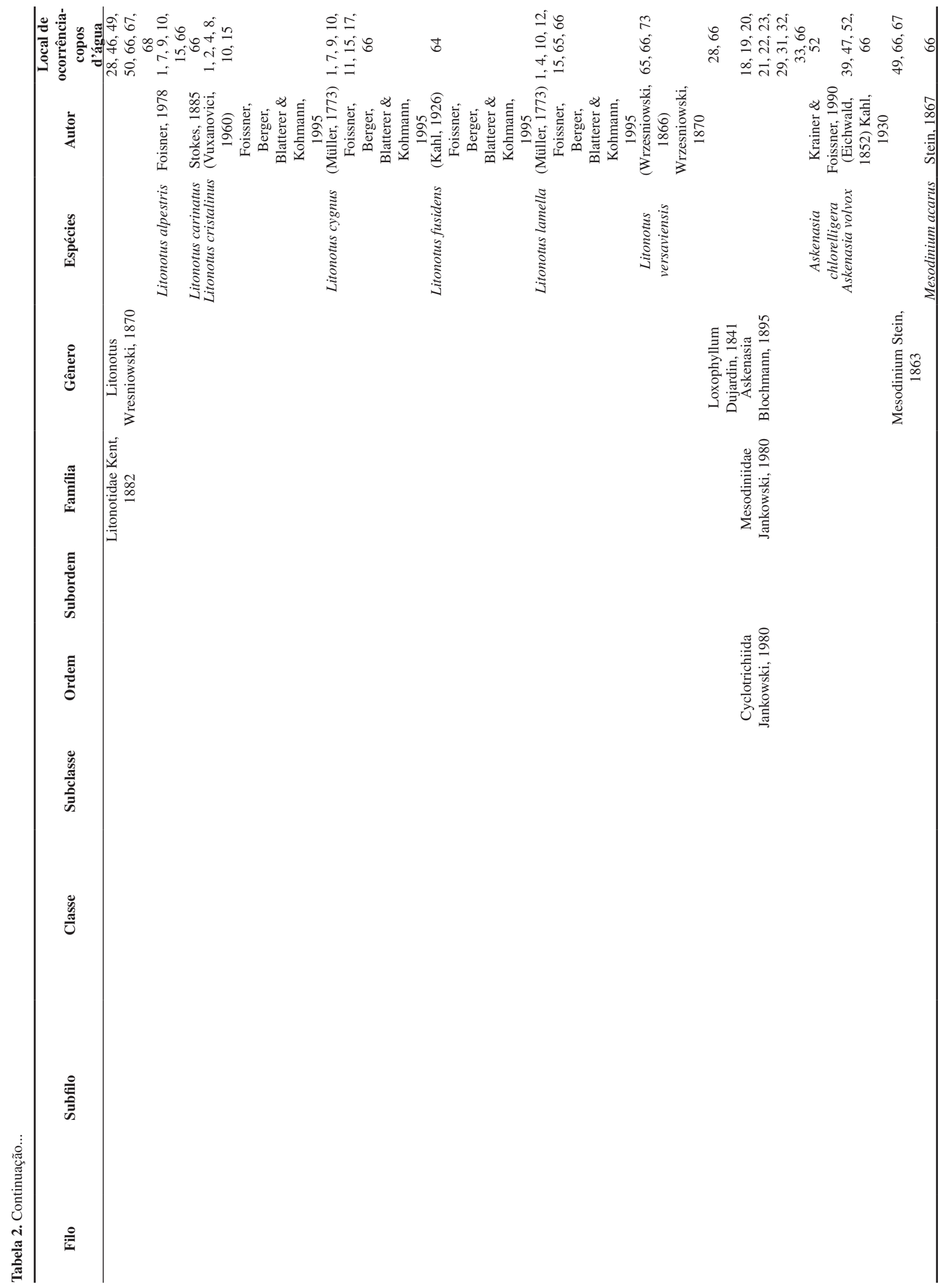




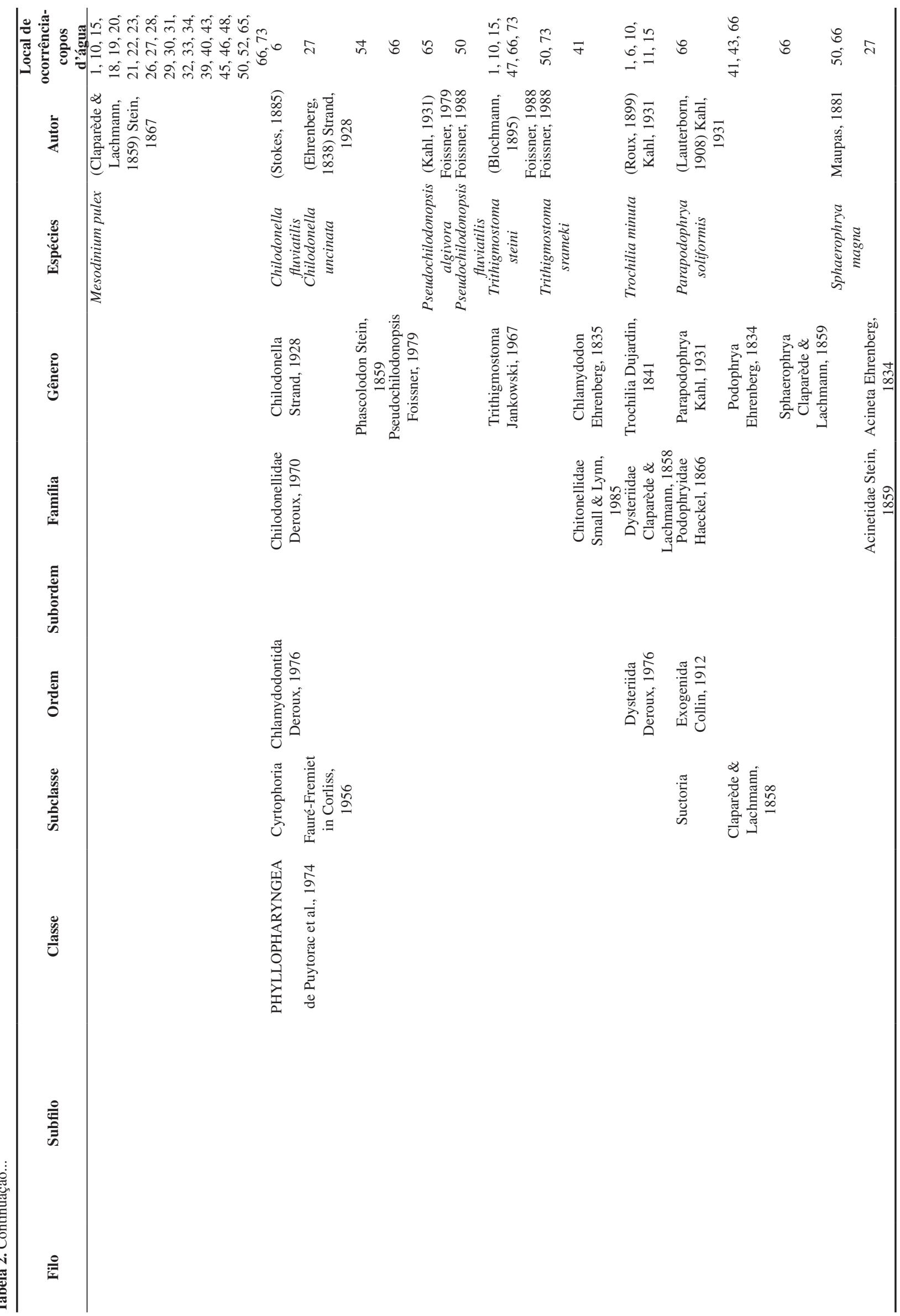


Regali-Seleghim, M.H. et al.

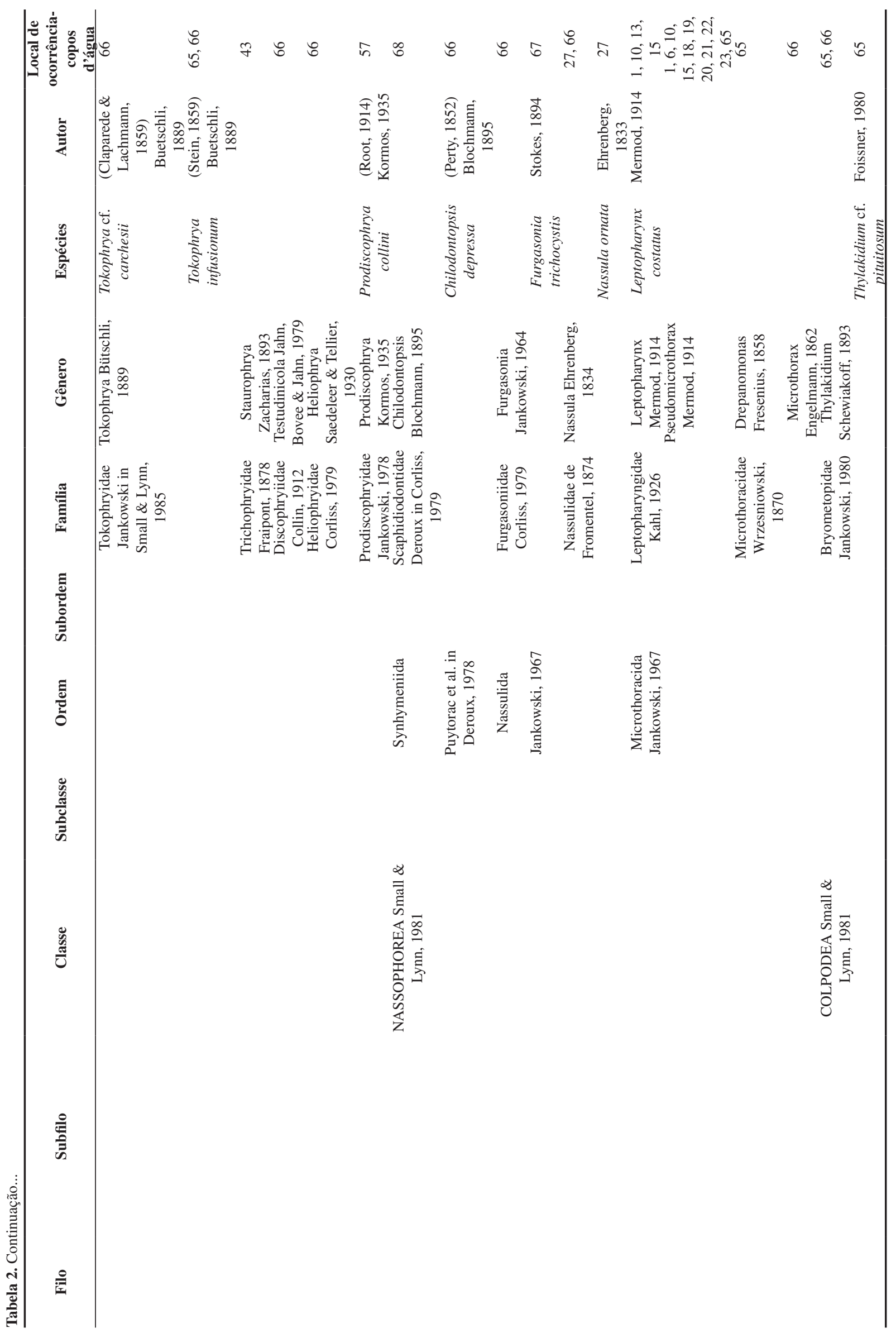




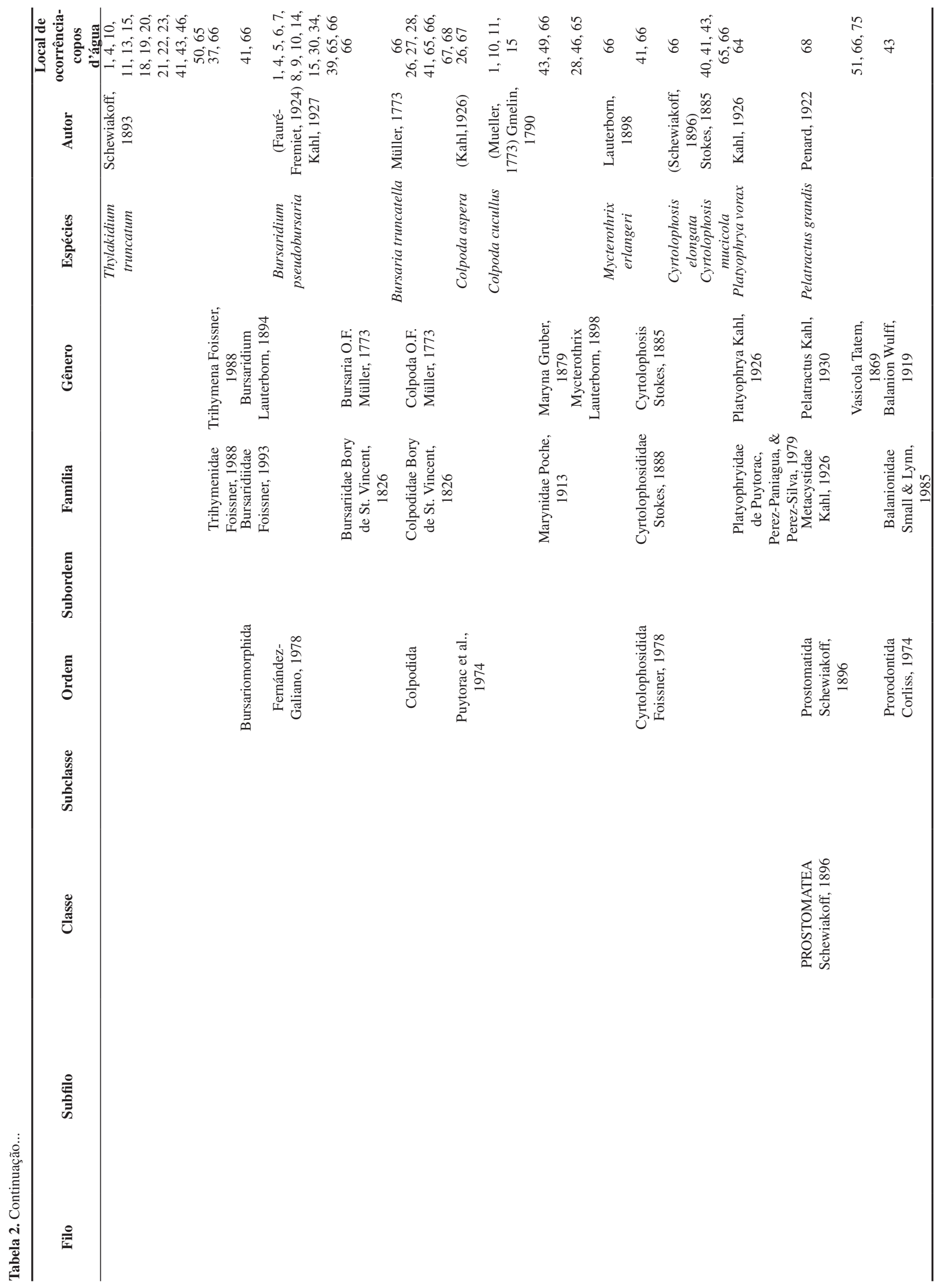


Regali-Seleghim, M.H. et al.

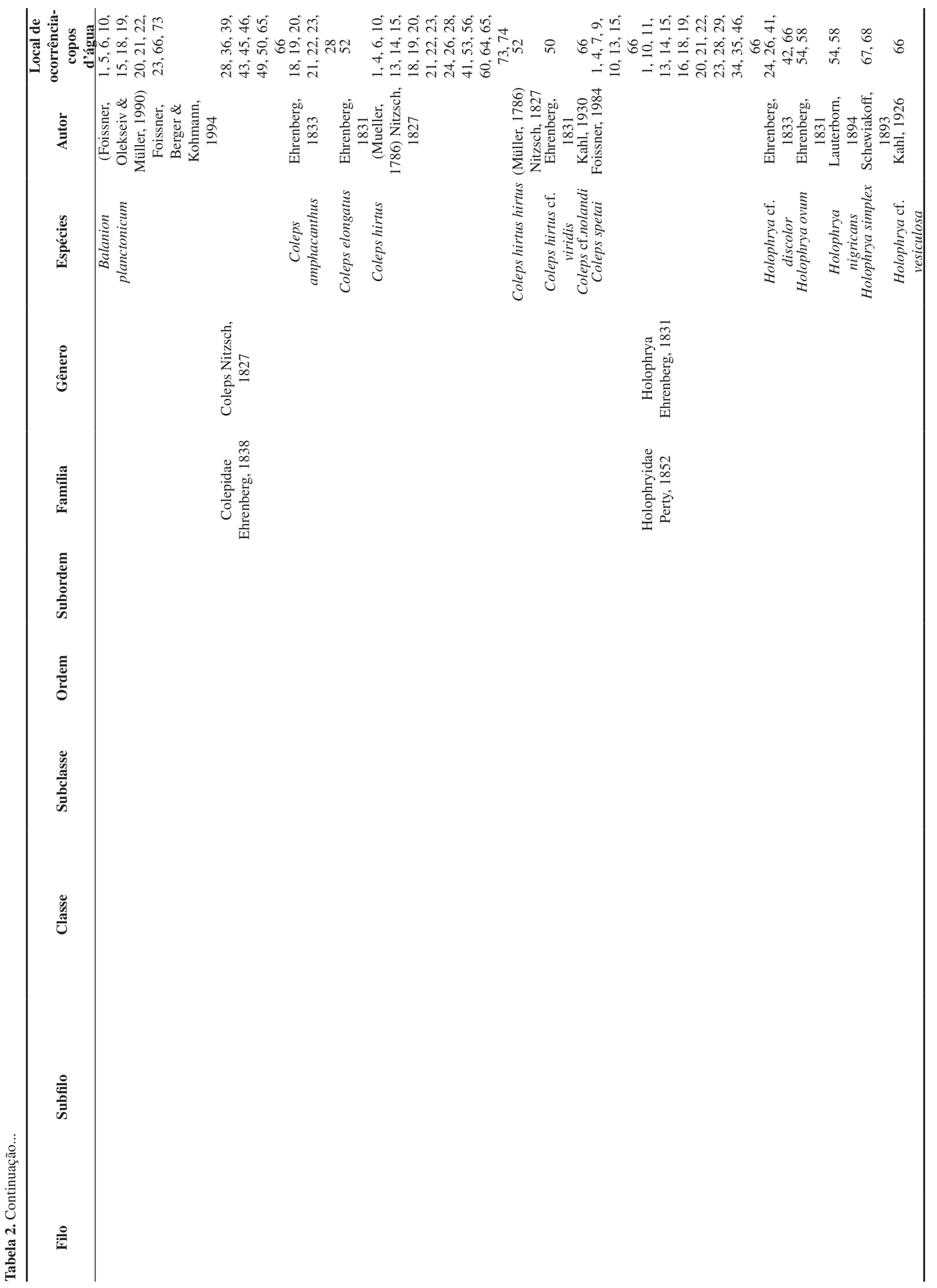




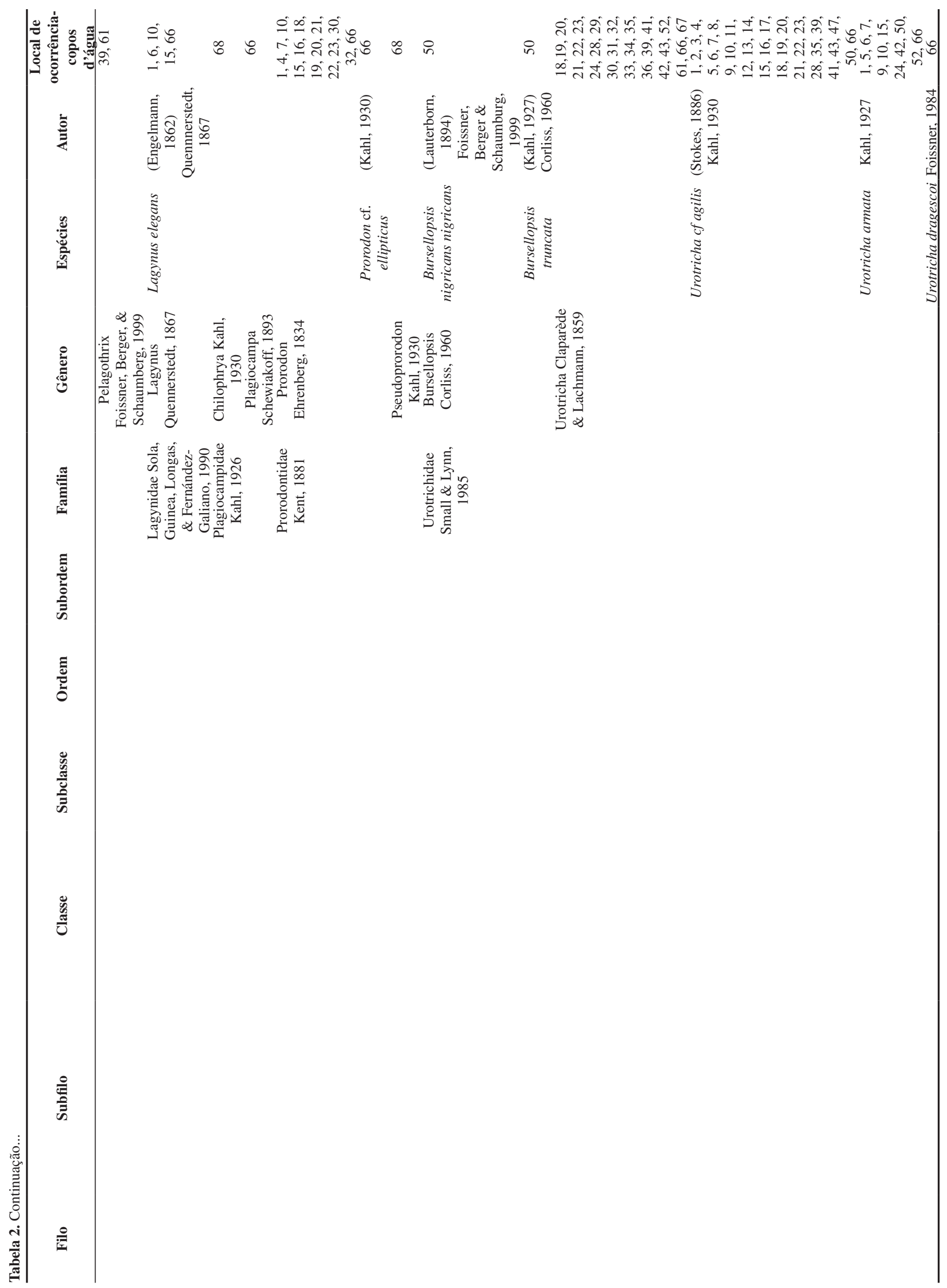


Regali-Seleghim, M.H. et al.

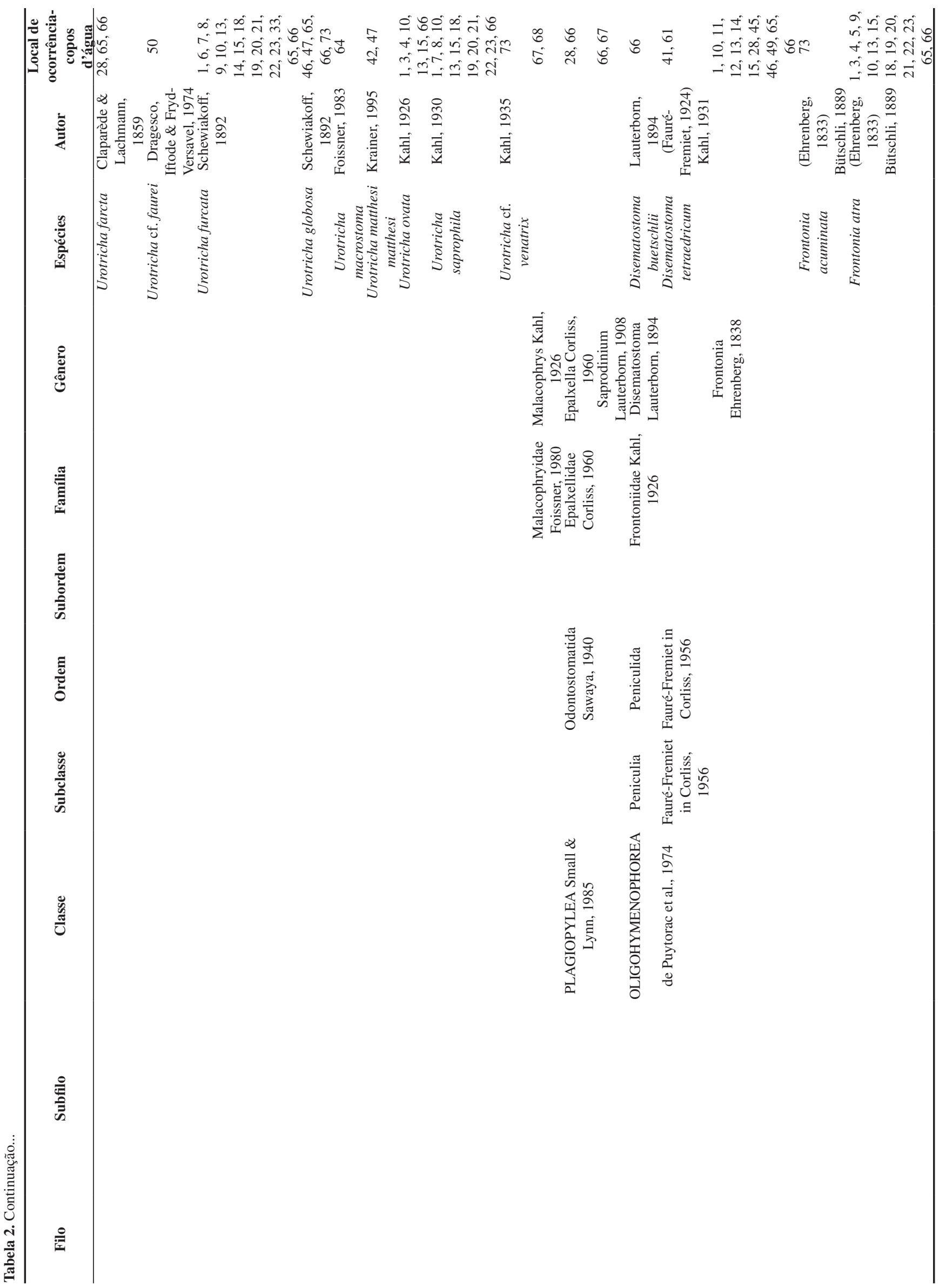




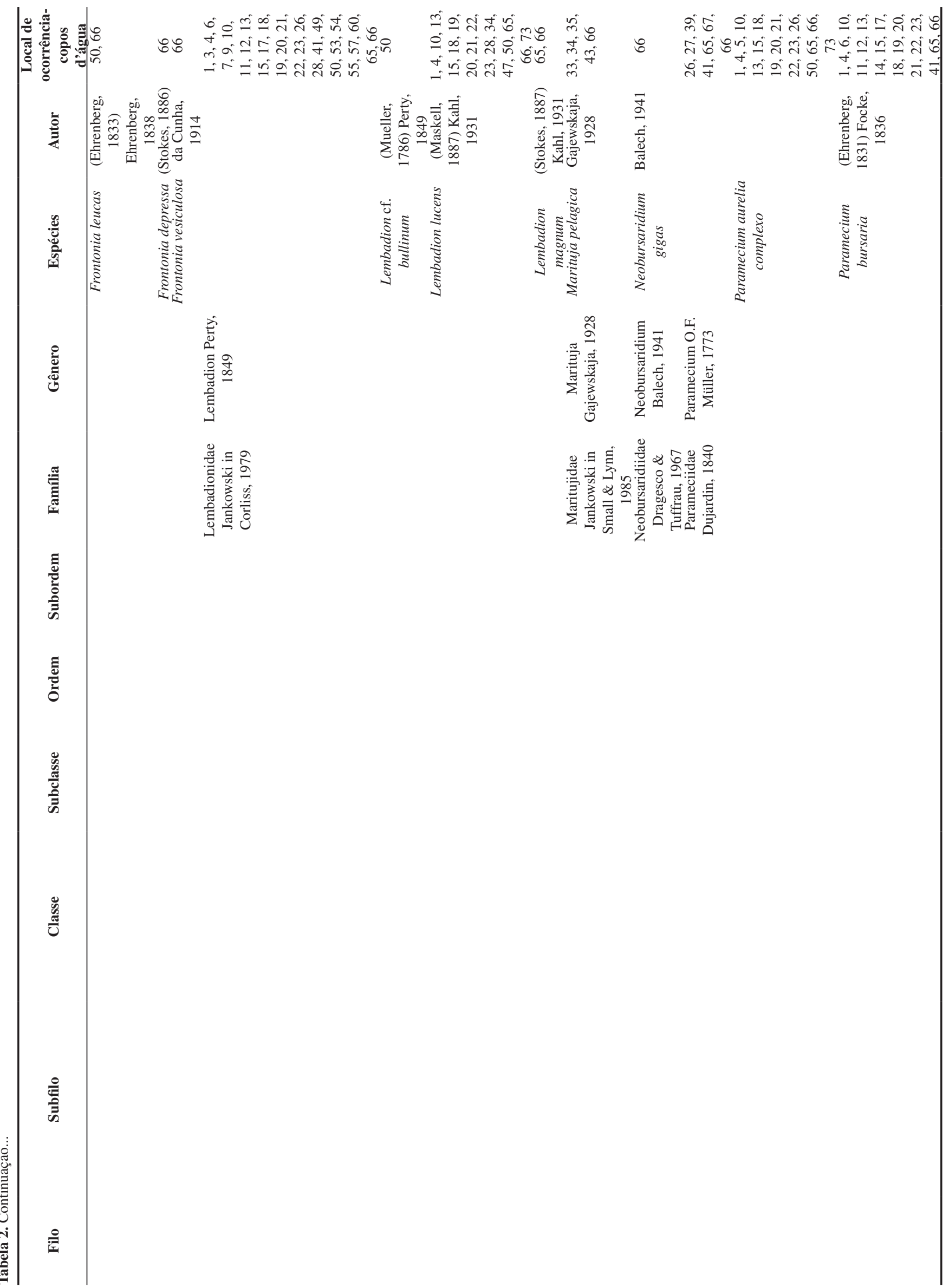


Regali-Seleghim, M.H. et al.

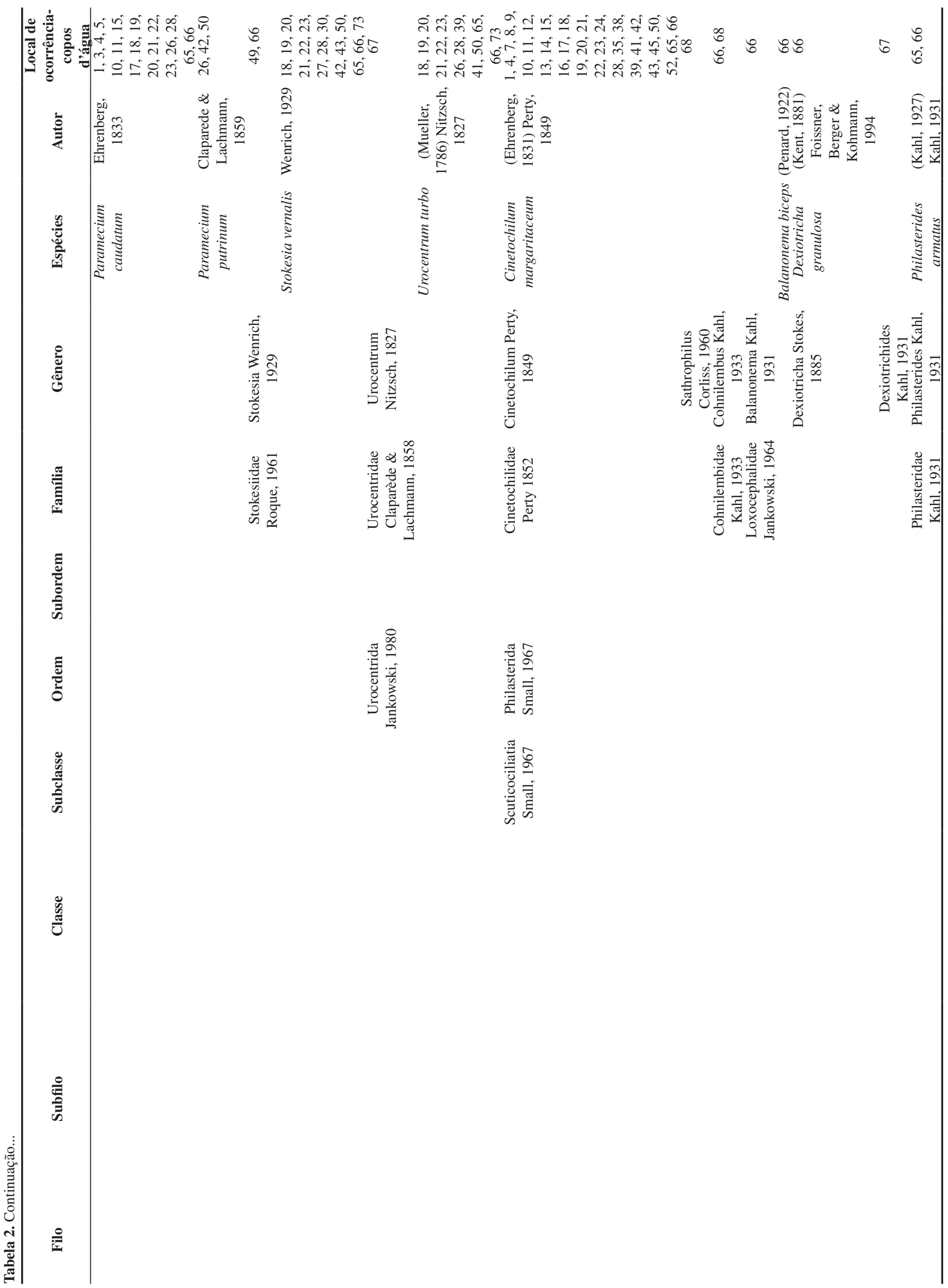




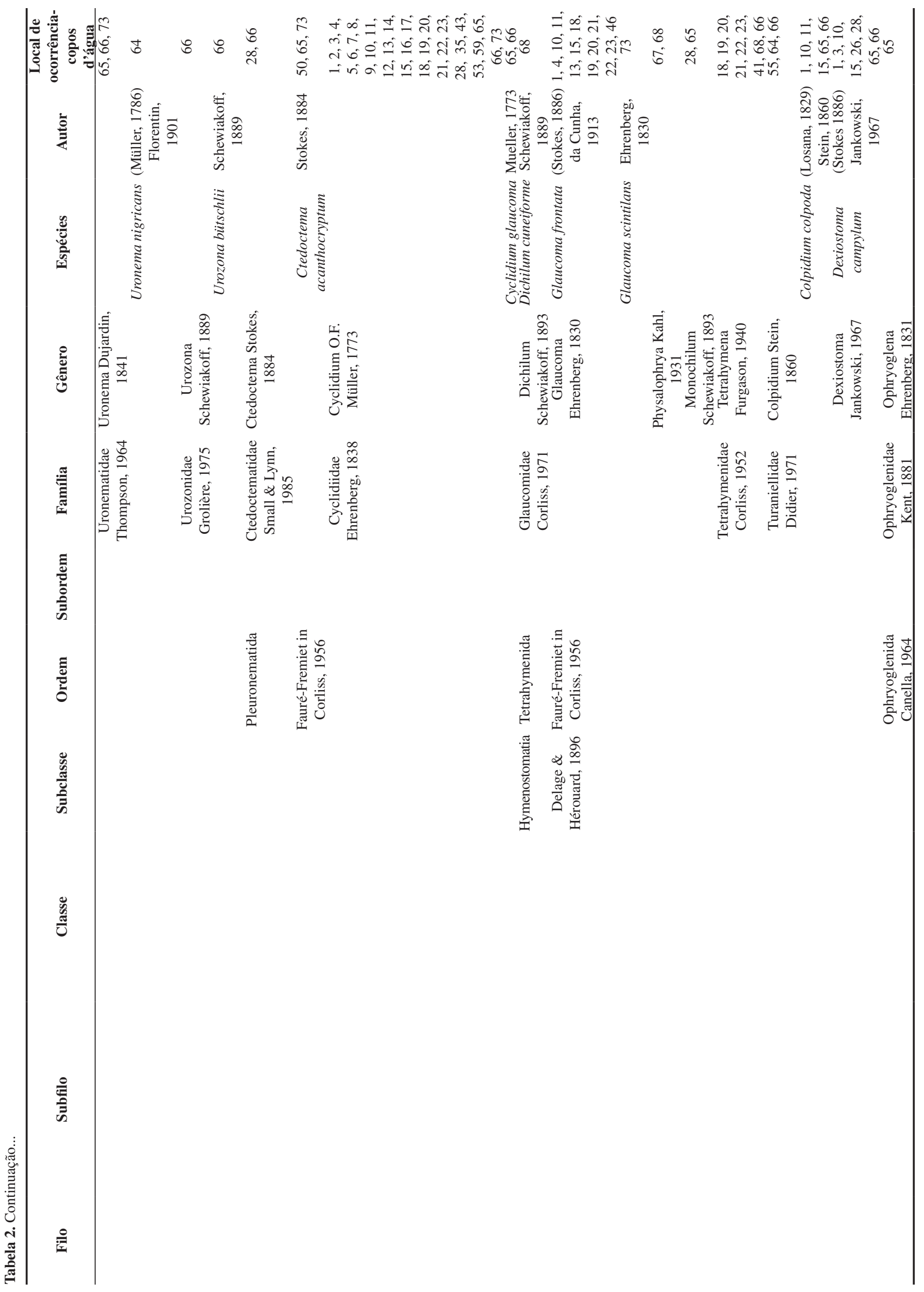


Regali-Seleghim, M.H. et al.

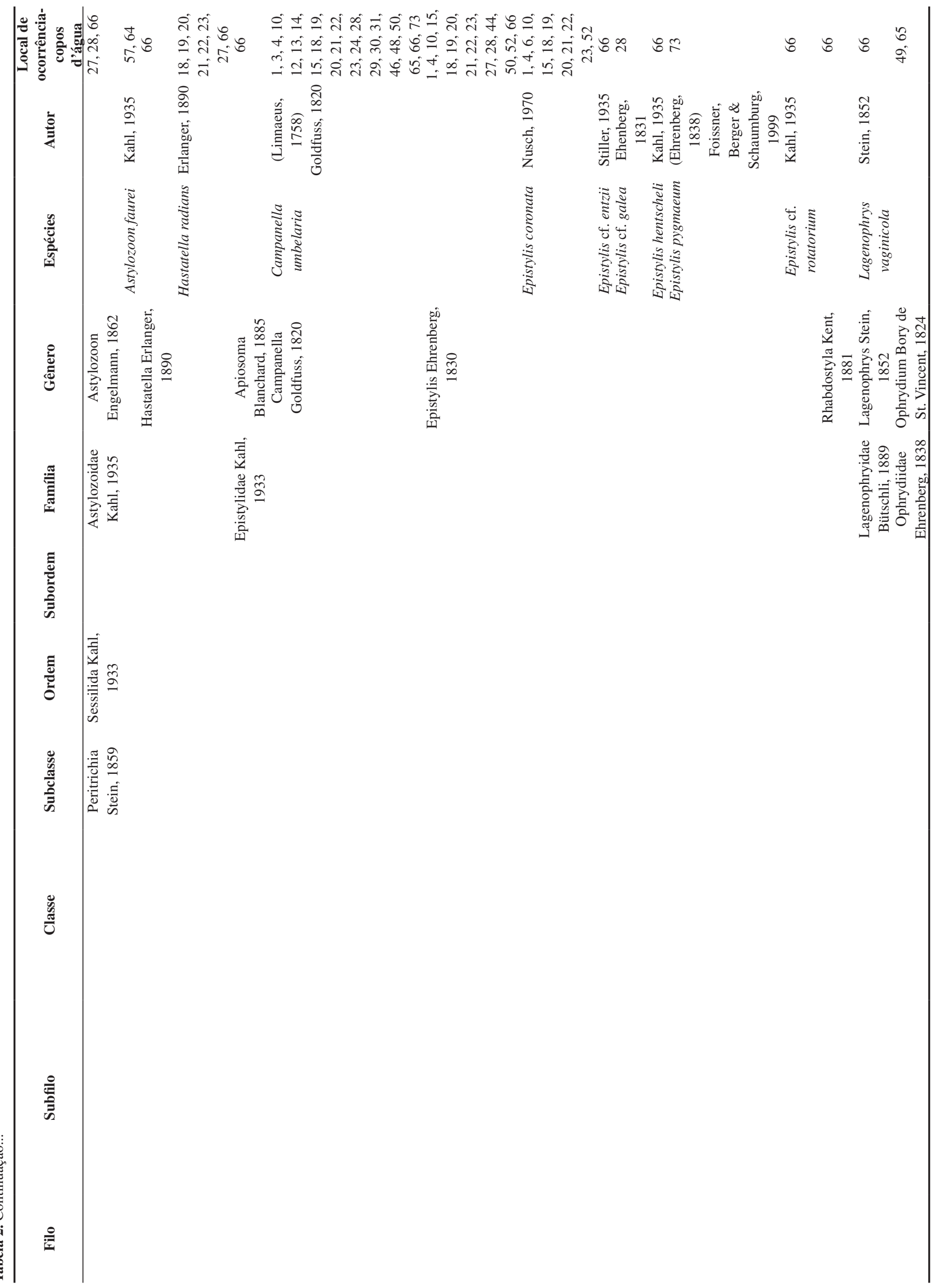


Protozoários de água doce do Estado de São Paulo

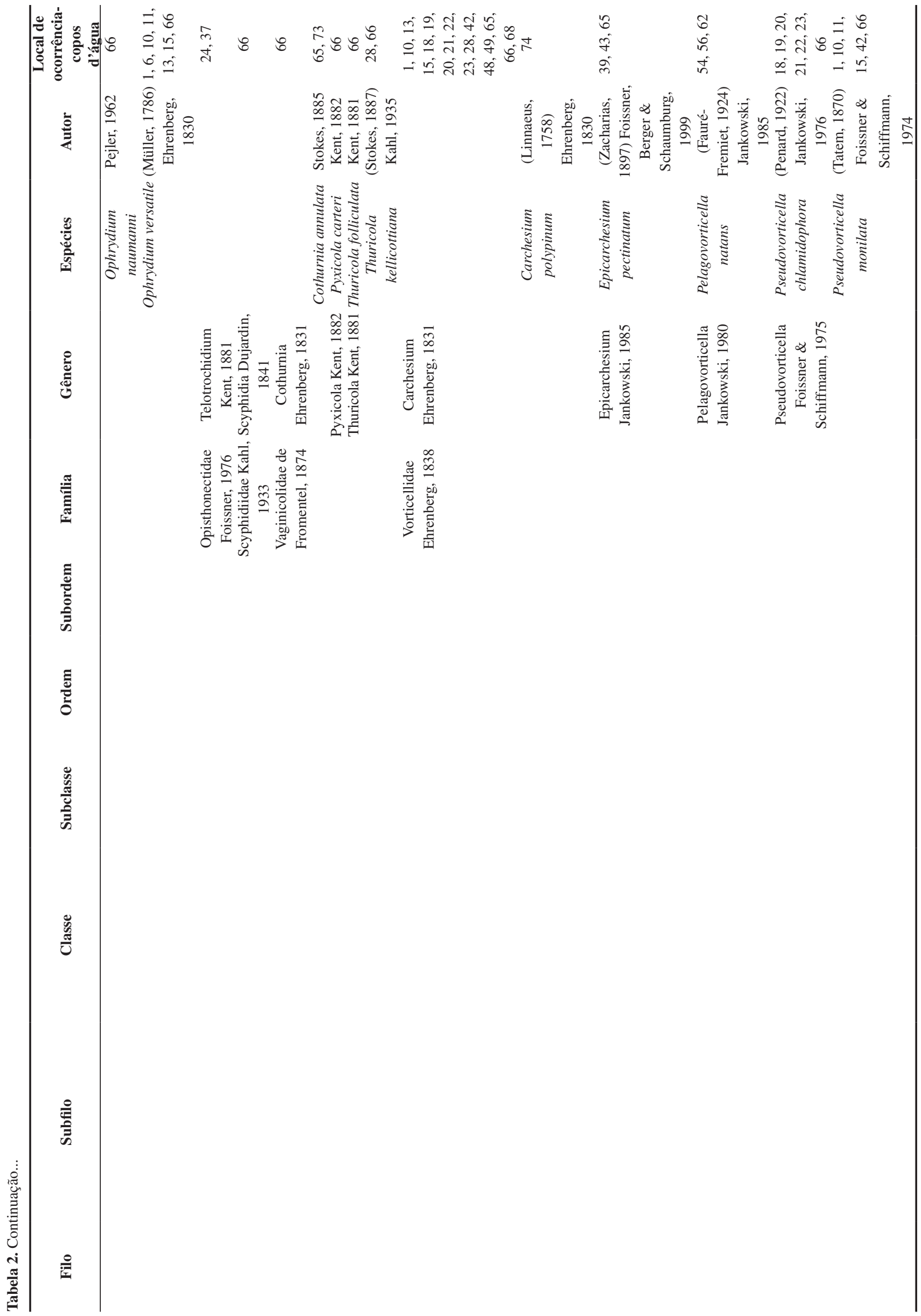


Regali-Seleghim, M.H. et al.

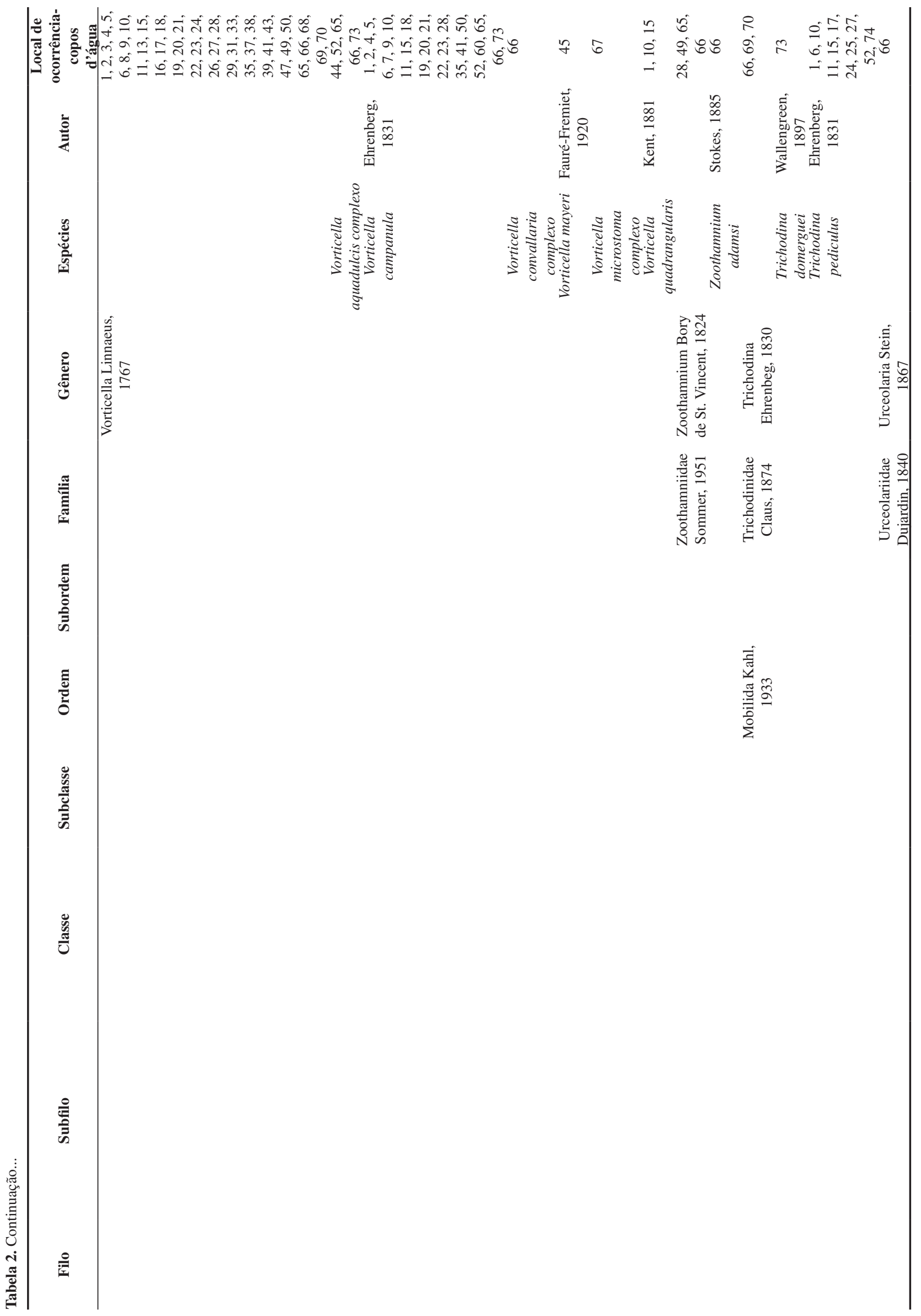




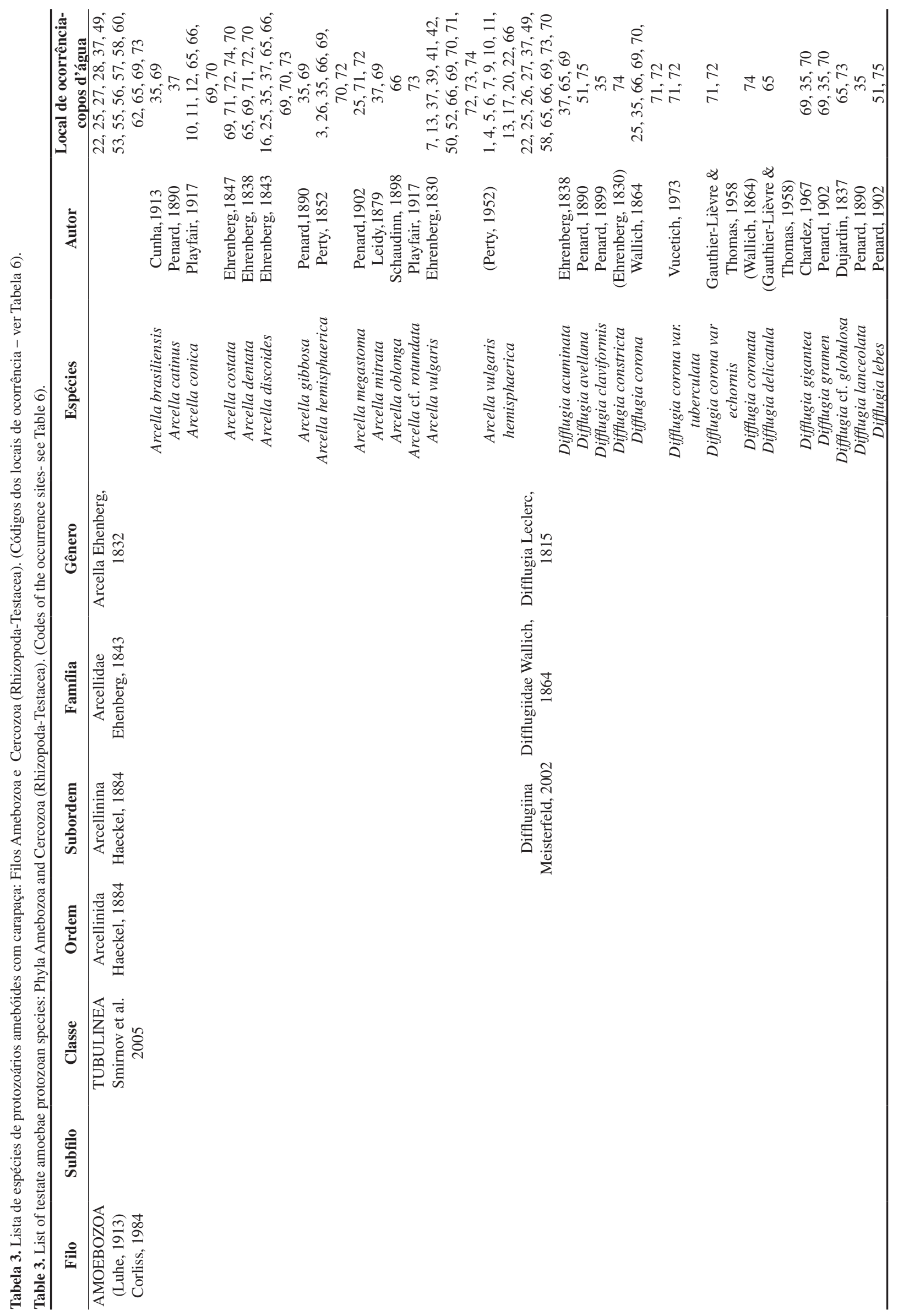


Regali-Seleghim, M.H. et al.

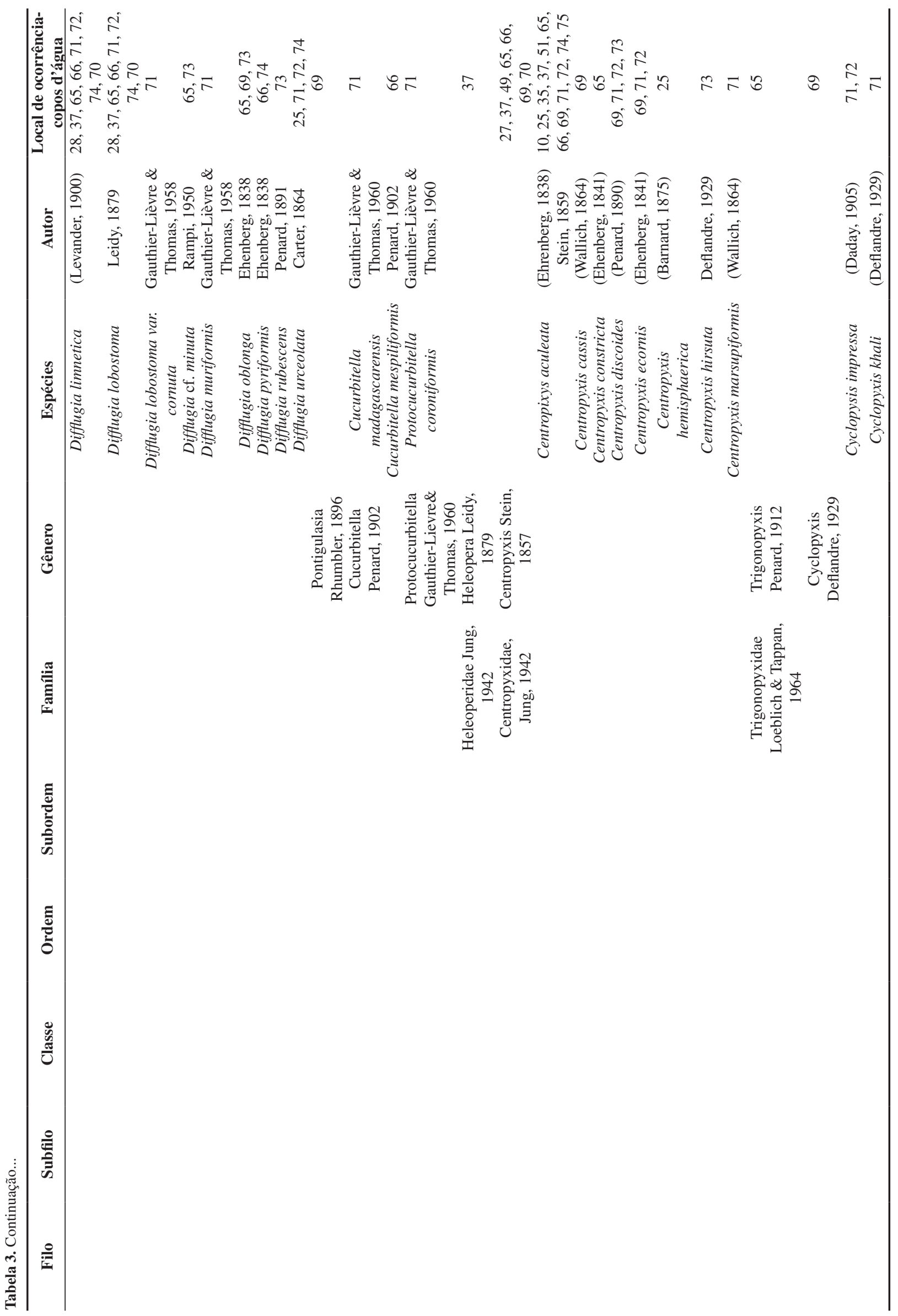


Protozoários de água doce do Estado de São Paulo

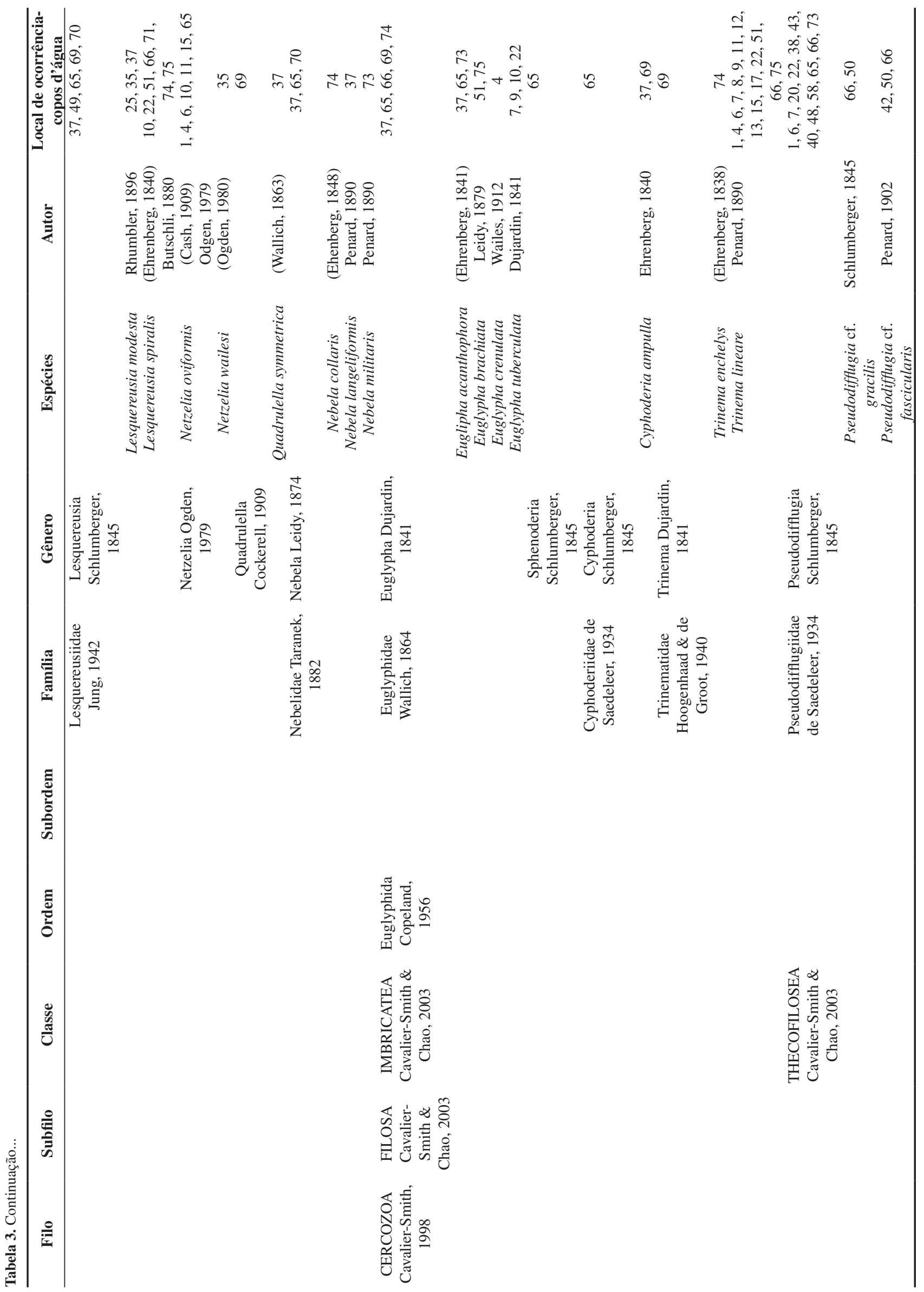


Regali-Seleghim, M.H. et al.

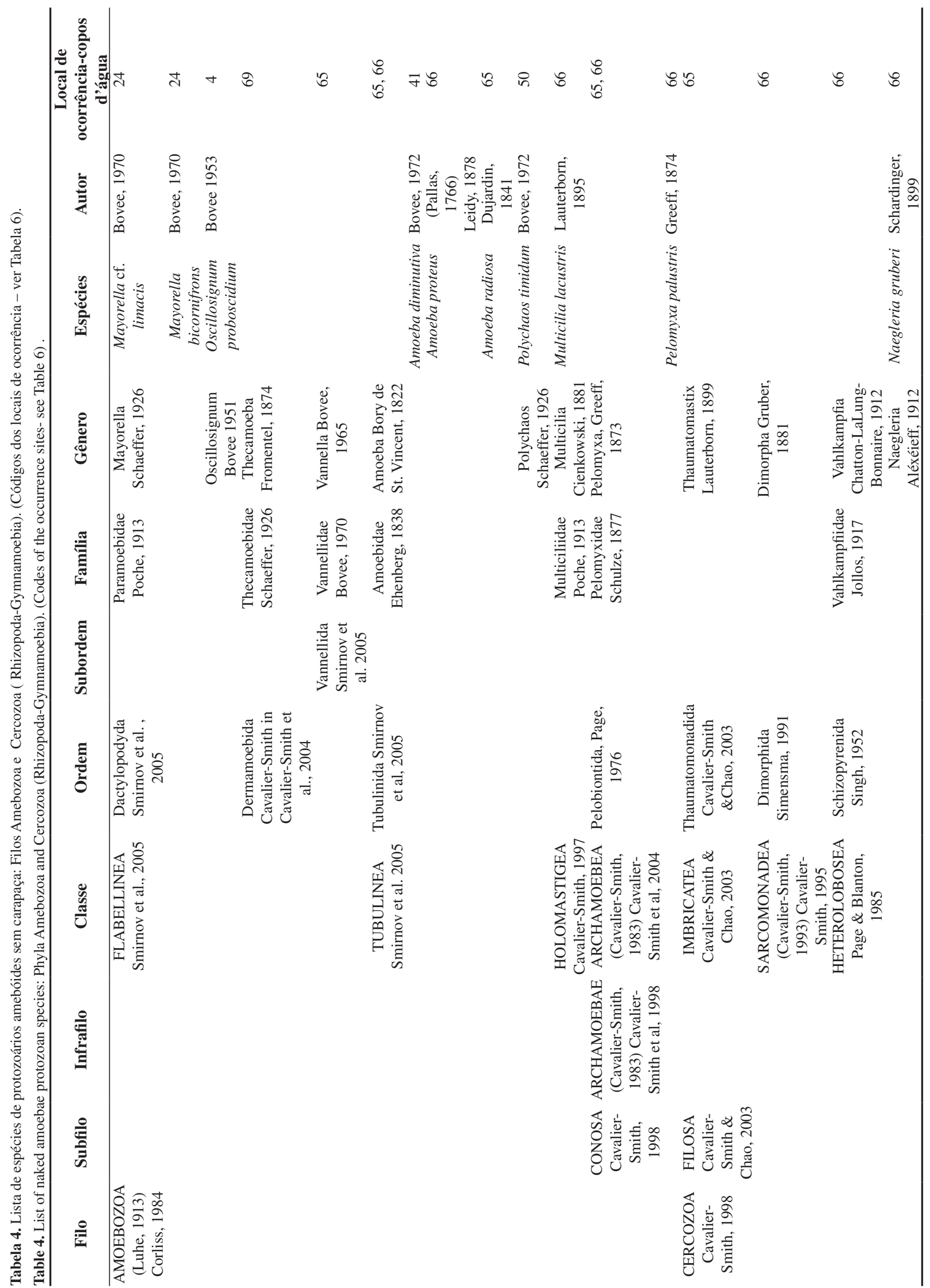


Tabela 5. Lista de espécies de protozoários heliozoários: Filos Heliozoa e Ochrophyta. (Códigos dos locais de ocorrência - ver Tabela 6).

Table 5. List of heliozoan protozoan species: Phyla Heliozoa and Ochrophyta. (Codes of the occurrence sites- see Table 6).

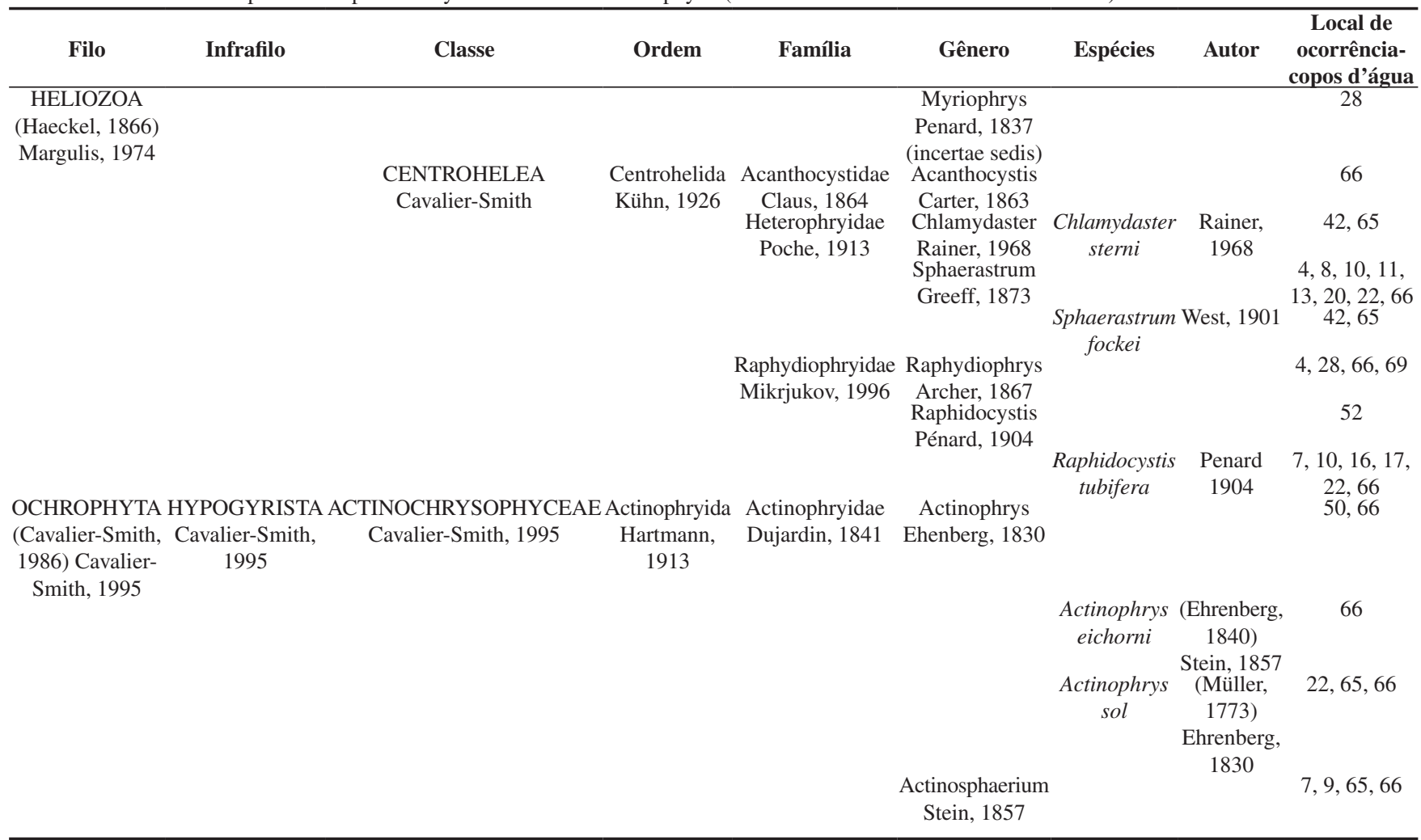

Tabela 6. Lista de espécies de protozoários flagelados heterotróficos que englobam os Filos: Euglenozoa, Ochrophyta, Choanozoa, Myzozoa, Apusozoa e Cryptisla. (Códigos dos locais de ocorrência - ver Tabela 6).

Table 6. List of flagellate protozoan species: Phyla Euglenozoa, Ochrophyta, Choanozoa, Myzozoa, Apusozoa e Cryptisla. (Codes of the occurrence sites- see Table 6).

\begin{tabular}{|c|c|c|c|c|c|c|c|c|}
\hline Filo & Classe & Ordem & Subordem & Família & Gênero & Espécies & Autor & $\begin{array}{c}\text { Local de } \\
\text { ocorrência- } \\
\text { copos d'água }\end{array}$ \\
\hline EUGLENOZOA & EUGLENOIDEA & Euglenida & & & Amphimonas & & & 66 \\
\hline \multirow[t]{24}{*}{$\begin{array}{c}\text { Cavalier-Smith, } \\
1981\end{array}$} & Butschli, 1884 & Butschli, 1884 & & & $\begin{array}{l}\text { Dujardin, } 1841 \\
\text { (incertae sedis) }\end{array}$ & & & \\
\hline & & & Sphenomonadina & & Anisonema & & & 65,66 \\
\hline & & & Leedale, 1967 & & Dujardin, 1841 & & & \\
\hline & & & & & Notosolenus & & & 65 \\
\hline & & & & & Stokes, 1884 & & & \\
\hline & & & Euglenina & & Astasia & & & 65,66 \\
\hline & & & Butschli, 1884 & & Dujardin, 1830 & & & \\
\hline & & & & & & $\begin{array}{c}\text { Astasia } \\
\text { klebsii }\end{array}$ & $\begin{array}{c}\text { Lemmermann, } \\
1910\end{array}$ & 66 \\
\hline & & & & & $\begin{array}{l}\text { Tropidoscyphus } \\
\text { Stein, } 1878\end{array}$ & & & 65 \\
\hline & & & Heteronematina & & Heteronema & & & 65 \\
\hline & & & Leedale, 1967 & & Dujardin, 1841 & & & \\
\hline & & Petalomonadida, & & & Petalomonas & & & 65 \\
\hline & & $\begin{array}{c}\text { Cavalier-Smith, } \\
1993\end{array}$ & & & Stein, 1859 & & & \\
\hline & & Peranemida & & & Peranema & & & 65,66 \\
\hline & & Butschli, 1884 & & & Dujardin, 1841 & & & \\
\hline & & & & & Entosiphon & & & 65 \\
\hline & & & & & Stein, 1878 & & & \\
\hline & & Rhabdomonadida & & & Distigma & & & 65 \\
\hline & & Leedale, 1967 & & & Ehrenberg, 1838 & & & \\
\hline & & & & & Rhabdomonas & & & 65 \\
\hline & & & & & Fresenius, 1858 & & & \\
\hline & KINETOPLASTEA & Bodonida & & Bodonidae & Bodo Ehrenberg, & & & 65,66 \\
\hline & (Honigberg, 1863) & Hollande, 1952 & & Butschli, 1887 & 1830 & & & \\
\hline & Margulis, 1974 & & & & & & & \\
\hline
\end{tabular}


Tabela 6. Continuação...

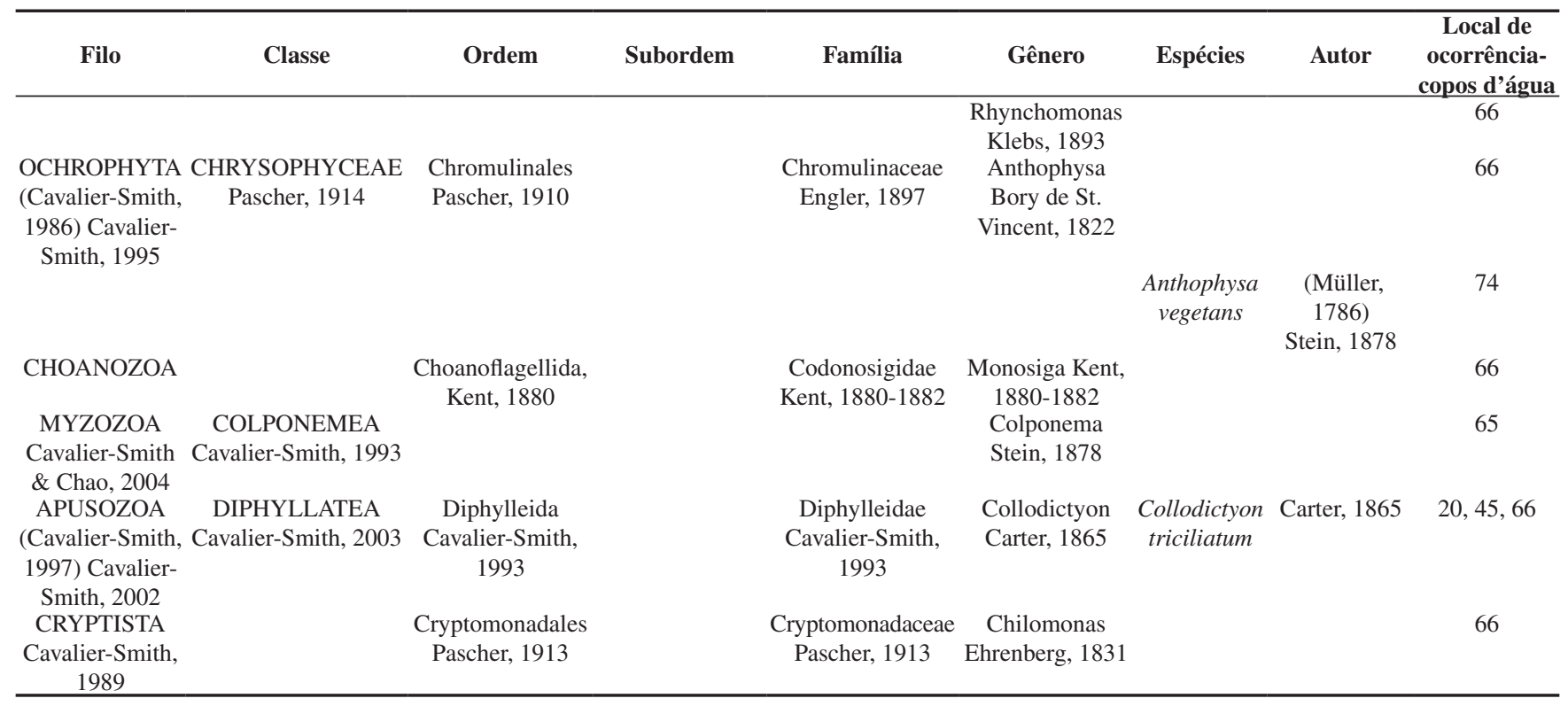

\section{Comentários sobre a riqueza de espécies do Estado de São Paulo quando comparada com a de outras regiões}

É difícil estabelecer comparação de riqueza de espécies de Protozoa que se tem conhecimento no Estado de São Paulo onde foram identificadas 304 espécies (ainda faltando análises para completar) com a riqueza de espécies de Protozoa de outras regiões, pois o estudo desse grupo taxonômico em outras regiões é feita por pesquisadores que estudam determinados ambientes aquáticos isoladamente, não havendo um grupo explorando uma grande área como foi feito no Estado de São Paulo, no Programa BIOTA/FAPESP. Portanto para avaliar esta questão é necessário um estudo intensivo sobre em outras regiões, aplicando a mesma metodologia de estudo.

\section{Principais avanços relacionados ao Programa BIOTA/FAPESP}

No primeiro levantamento do número de espécies de protozoários no Estado de São Paulo, feito por Godinho e Regali-Seleghim em 1999, foram analisados 8 ambientes onde foram encontrados 148 gêneros e 69 espécies de protozoários. O Programa BIOTA/ FAPESP deu oportunidade de explorar maior número de corpos de água inseridos nas 22 UGRHI do Estado de São Paulo o que permitu um incremento de 70 gêneros, totalizando 218 gêneros e 304 espécies de protozoários (Tabela 7). Proporcionalmente o maior aumento nesse atual levantamento foi com relação ao número de espécies, o que pode indicar um melhor treinamento taxonômico das pessoas que executaram os trabalhos mais recentes.

Analisando por grupo de protozoários, os mais bem representados foram os ciliados com 160 gêneros e 219 espécies e os menos representados foram os heliozoários, amebas nuas e flagelados. Tais proporções encontradas para os diferentes grupos provavelmente não são as mesmas das reais que existem nos locais. Isso porque, nos diferentes trabalhos avaliados, é frequente o relato de organismos não identificados que não foram computados. Essas dificuldades para a identificação são mais frequentes em grupos de tamanho menor como, por exemplo, o dos flagelados. Outros fatores que afetam as proporções encontradas para cada grupo são relacionados com dificuldades metodológicas como, por exemplo, o fato de um mesmo agente fixador ter diferente desempenho nos diferentes grupos de protozoários. Outro exemplo de problema metodológico inerente a determinado grupo se refere à identificação das amebas nuas que deve ser feita em amostras vivas que, dependendo da distância do ambiente em relação ao laboratório, e das rotinas de coleta de determinados projetos, pode se tornar inviável.

Com relação às espécies encontradas no Estado, algumas são muito frequentes nos diversos ambientes como, por exemplo, Halteria grandinella (Müller, 1773) Dujardin, 1841 que ocorreu em 51 dos 75 ambientes estudados, Rimostrombidium humile (Penard, 1922) Petz \& Foissner, 1992 que ocorreu em 34, Cinetochilum margaritaceum (Ehrenberg, 1831) Perty, 1849 que ocorreu em 32, Urotricha agilis (Stokes, 1886) Kahl, 1930 que ocorreu em 31 , etc. Por outro lado, dos 471 taxa encontrados, 213 podem ser considerados raros, pois foram encontrados somente em um ambiente dos 75 analisados. Duas espécies de distribuição geográfica limitada foram encontradas por Regali-Seleghim (2001, observações pessoais) no Reservatório do Monjolinho. Uma delas é um primeiro relato para o Brasil (Neobursaridium gigas Balech, 1941), e a outra é o primeiro relato para a América do Sul (Loxodes rex Dragesco, 1970). Neobursaridium gigas Balech, 1941 já havia sido relatado na Argentina, Uganda e Tailândia e Loxodes rex Dragesco, 1970 somente tinha sido encontrado na África e Tailândia (Esteban et al. 2001).

\section{Principais grupos de pesquisa no Estado de São Paulo}

Com o Projeto BIOTA/FAPESP foi possível formar um grupo de pesquisa na UFSCar, dedicado exclusivamente a esse grupo de organismos, explorando um maior numero de ambientes aquáticos, abrangendo grande parte do Estado de São Paulo e obtendo resultados mais precisos para a avaliação da diversidade. Esse grupo de pesquisa formado por docentes da UFSCar especialistas em protozoários, juntamente com estudantes da graduação e pós-graduação teve atuação durante a vigência do Programa BIOTA/FAPESP (19992003) e continuaram, após seu término.

No Brasil, dos 19 pesquisadores que trabalham com protozoários, 4 são do Rio de Janeiro; 4 do Rio Grande do Sul ; 3 de Minas Gerais; 2 do Paraná; 2 de São Paulo; 1 da Paraíba; 1 do Rio Grande do Norte; 1 do Distrito Federal e 1 do Mato Grosso. 


\section{Principais coleções, acervos}

No exterior existem coleções de culturas que incluem espécimens de protozoários como a CCAP (Culture Collection of Algae and Protozoa) no Reino Unido; a ATCC (American Type Culture Collection) e a Carolina Biological Supply Company nos EUA e a SCCAP (Scandinavian Culture Collection of Algae \& Protozoa) na Dinamarca. Nelas, existem poucas linhagens de protozoários disponíveis, sendo que a maior parte dos acervos é de linhagens de algas. A maior parte das linhagens disponíveis de protozoários é de amebas nuas, de ciliados e de flagelados.

No Brasil, embora tentativas tenham sido feitas para a criação de coleções de cultura de referência de protozoários de vida livre, existem apenas algumas coleções informais com linhagens mantidas em cultura (não axênica) e usadas para pesquisa e ensino em universidades ou escolas. Elas são mantidas sem financiamento específico e fornecem material sem cobrança. Essas coleções sofrem, portanto, com a falta de recursos para a compra de material e também com a falta de mão-de-obra especializada para o isolamento de novas linhagens, a execução dos meios de cultura e as repicagens, que são necessárias com frequência para sua manutenção. Como exemplo, existe uma coleção informal no Laboratório de Ecologia de Microrganismos Aquáticos (Lema) da Universidade Federal de
São Carlos (UFSCar) que possui pelo menos quatorze linhagens de protozoários mantidas em cultura. Essas culturas são utilizadas em pesquisa e ensino em disciplinas na UFSCar, além de serem fornecidas gratuitamente, para aulas, em outras instituições de ensino superior, médio e fundamental da região. Os protozoários mantidos em cultura são dez ciliados, dois flagelados, uma tecameba e uma ameba nua, respectivamente: Blepharisma undulans americanus Suzuki, 1954; Colpidium colpoda (Losana, 1829) Stein, 1860; Dexiostoma campylum (Stokes 1886) Jankowski, 1967; Euplotes sp.; Halteria grandinella (Müller, 1773) Dujardin, 1841; Paramecium aurelia complexo; Paramecium bursaria (Ehrenberg, 1831) Focke, 1836; Paramecium caudatum Ehrenberg, 1833; Spirostomum ambigumm (Müller, 1786) Ehrenberg, 1835; Spirostomum teres Claparede \& Lachmann, 1858; Astasia klebsii Lemmermann, 1910; Chilomonas sp.; Arcella sp. e Naegleria gruberi Schardinger, 1899.

Segundo Regali-Seleghim (2006) existem, para fins taxonômicos, coleções de lâminas preparadas de espécimens-tipo, que são mantidas muitas vezes em laboratórios ou museus (e.g. Museu de História Natural de Paris). Segundo Corliss (1972), na tentativa de centralizar e facilitar o acesso desse material a taxonomistas do mundo todo foi criada, em 1963, na Universaidade de Illinois, a "Coleção Internacional de Espécies-Tipo de Ciliados". Posteriormente, segundo Cole (1994), tal coleção foi transferida para o Museu Nacional dos

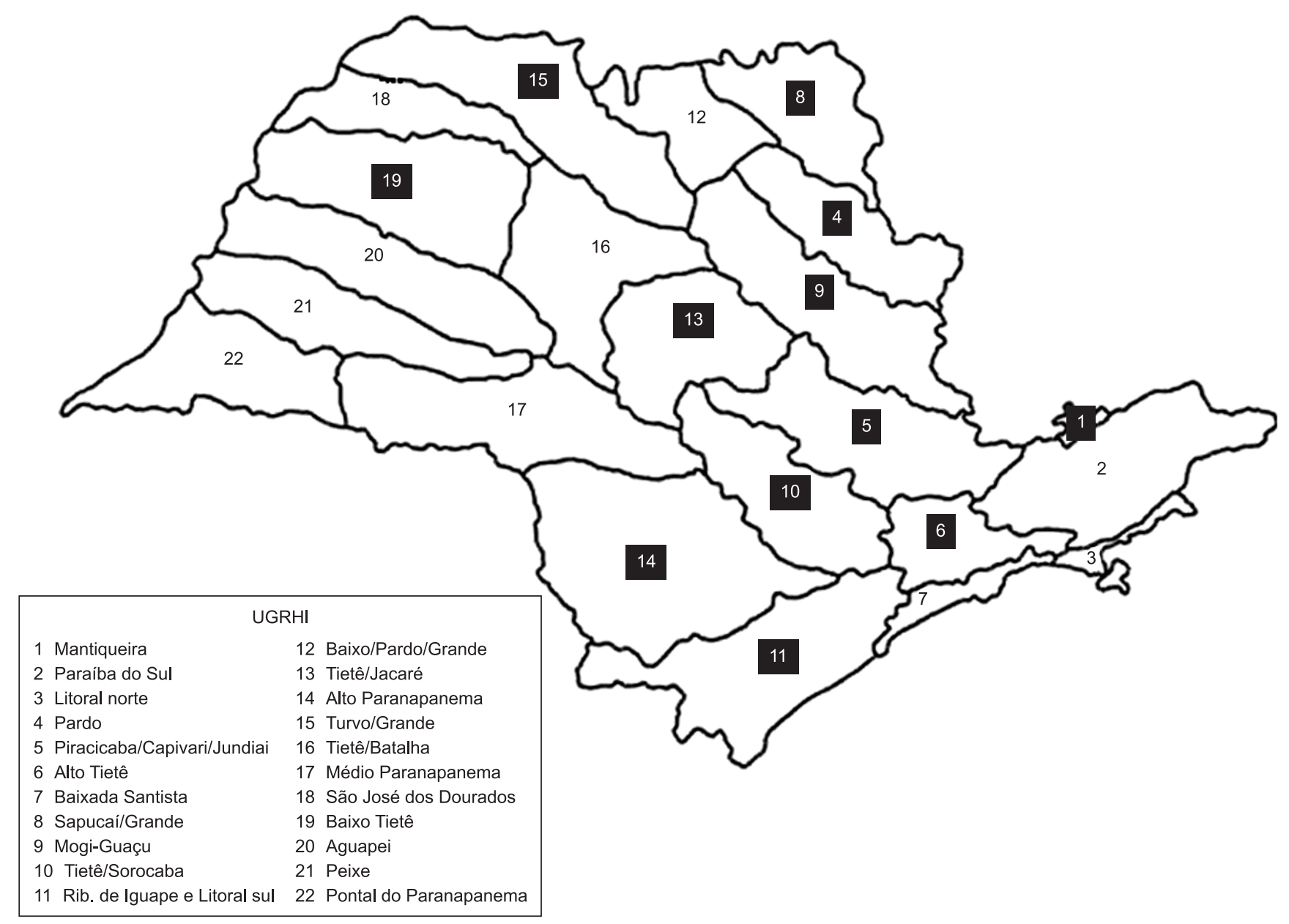

Figura 1. Estado de São Paulo com as Unidades de Gerenciamento de Recursos Hídricos (UGRHI). Nas UGRHI destacadas em negrito as comunidades protozooplantônicas foram estudadas em alguns corpos d'água.

Figure 1. São Paulo State with the Water Resources Management Units (UGRHI). In the marked UGRHI the protozoan communities were studied in some water bodies. 


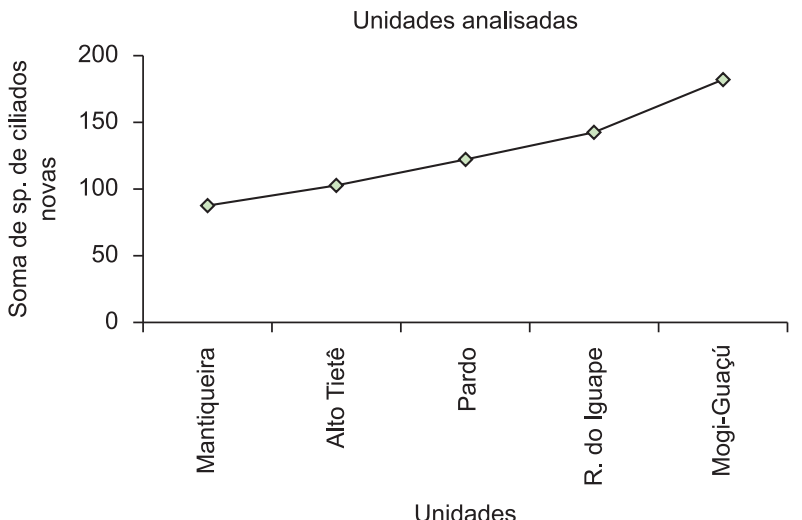

Figura 2. Curva cumulativa de número de espécies de ciliados em relação ao número de corpos de água analisados nas UGRHI Mantiqueira, Alto Tietê, Pardo, Ribeira do Iguape e Mogi-Guaçu do Estado de São Paulo.

Figure 2. Cumulative curve of the number of ciliate species found in the water bodies analyzed on the Water Resources Management Units of the São Paulo State (Mantiqueira, Alto Tietê, Pardo, Ribeira do Iguape and Mogi-Guaçu).

Tabela 7. Gêneros, espécies e diferentes taxa de protozoários de água doce detectados em 75 ambientes no Estado de São Paulo.

Table 7. Genera, species and different freshwater protozoan taxa registered in 75 environments from São Paulo State.

\begin{tabular}{lccc}
\hline \multicolumn{1}{c}{ Grupos } & $\begin{array}{c}\text { Número de } \\
\text { gêneros }\end{array}$ & $\begin{array}{c}\text { Número de } \\
\text { espécies }\end{array}$ & $\begin{array}{c}\text { Número total de } \\
\text { diferentes taxa }\end{array}$ \\
\hline Ciliados & 160 & 219 & 338 \\
Tecamebas & 20 & 67 & 84 \\
Amebas nuas & 12 & 10 & 17 \\
Heliozoários & 8 & 5 & 12 \\
Flegelados & 18 & 3 & 20 \\
heterotróficos & & & \\
Total & 218 & 304 & 471 \\
\hline
\end{tabular}

Estados Unidos da "Smitsonian Institution" (Washington) onde está atualmente depositada. A coleção foi ampliada para os outros grupos de protozoários e hoje é chamada de "Coleção Internacional de Espécies-Tipo de Protozoários”. Segundo essa autora, em outubro de 1992 a coleção incluía membros de cinco filos (Ciliophora, Sarcomastigophora, Apicomplexa, Microspora e Myxozoa) com aproximadamente 542 espécies.

Apesar da "Coleção Internacional de Espécies-Tipo de Protozoários" existir até os dias de hoje, algumas outras coleções de espécies-tipo de protozoários foram formadas. Uma importante foi montada no Centro de Biologia de Lintz na Áustria que, segundo Aescht (2003), conta com 677 ciliados e 13 outros protozoários, a maioria contribuições de Wilhelm Foissner, especialista em taxonomia de ciliados.

No Brasil a única coleção de lâminas de protozoários (ciliados) está sediada no Laboratório de Protistologia do Departamento de Zoologia do Instituto de Biologia da Universidade Federal do Rio de Janeiro (UFRJ) sob a curadoria do prof Dr. Inácio Domingues da Silva Neto.

\section{Principais lacunas do conhecimento}

Apesar dos dados apresentados aqui mostrarem que o Programa BIOTA/FAPESP teve um importante efeito indutor no aumento do conhecimento dos protozoários no Estado e na formação de recursos humanos, os dados também mostram que ainda tem muito para ser feito, pois vários importantes ambientes e bacias não foram estudados ou foram pouco estudados. Cabe destacar ainda aqui a total ausência de estudos sobre protozoários de solo no Estado de São Paulo, embora o solo não seja o objeto desse trabalho. Mesmo sem o incentivo das agências de fomento à pesquisa, houve também um avanço em técnicas de cultivo de protozoários e no número de linhagens mantidas em cultura que ampliarão o potencial de utilização desses recursos biológicos em ensino e pesquisa de caráter ecológico e biotecnológico nos próximos anos.

\section{Perspectivas de pesquisa em protozoa nos próximos 10 anos}

A perspectiva de pesquisa em Protozoa nos próximos 10 anos deve-se concentrar ainda no Estado de São Paulo, dando continuidade ao estudo taxonômico dos protozoários do material já coletado nos corpos de água de outras UGRHI. Para isso é necessário formar grupo de pesquisa sólido, constituído por pesquisadores especializados em protozoários nos diversos Filos, juntamente com o apoio da Pósgraduação na formação de recursos humanos e apoio dos órgãos de pesquisa concedendo bolsas de mestrado, doutorado e pós-doutorado.

\section{Referências Bibliográficas}

ADL, S.M., SIMPSON, A.G.B., FARMER, M.A., ANDERSEN, R.A., ANDERSON, O.R., BARTA, J.R., BOWSER, S.S., BRUGEROLLE, G., FENSOME, R.A., FREDERIC, S., JAMES, T.Y., KARPOV, S., KUGRENS, P., KRUG, J., LANE, C.E., LEWIS, L.A., LODGE, J., LUNN, D.H., MANN, D.G., McCOURT, R.M., MENDOZA, L., MOESTRUP, Ø., MOZLEY-STANDRIDGE, S.E., NERAD, T.A., SHEARER, C.A., SMIRNOV, A.V., SPIEGEL, F.W. \& TAYLOR, M.F.J.R. 2005. The new higher level classification of eukaryotes with emphasis on the taxonomy of protists. J. Eukaryot. Microbiol. 52(5):399-451. PMid:16248873. http:// dx.doi.org/10.1111/j.1550-7408.2005.00053.x

ADL, S.M., LEANDER, B.S., SIMPSON, A.G.B., ARCHIBALD, J.M., ANDERSON, O.R., BASS, D., BOWSER, S.S., BRUGEROLLE, G., FARMER, M.A., KARPOV, S., KOLISKO, M., LANE, C.E., LODGE, D.J., MANN, D.G., MEISTERFELD, R., MENDOZA, L., MOESTRUP, Ø., MOZLEY-STANDRIDGE, S.E., SMIRNOV, A.V. \& SPIEGEL, F. 2007. Diversity, nomenclature, and taxonomy of protists. Syst. Biol. 56(4):684-689. PMid:17661235. http://dx.doi. org/10.1080/10635150701494127

AESCHT, E. 2003. Typen-Liste der Sammlung "Wirbellose Tiere" (ohne Insekten) am Biologiezentrum Linz. Beitr. Naturk. Oberösterreichs 12:377-406.

ARANTES JUNIOR, J.D., RIETZLER, A.C., ROCHA, O. \& REGALISELEGHIM, M.H. 2004. Caracterização das populações de protozoários (Ciliophora e Rhizopoda) no reservatório de Salto Grande, Americana, SP. In Reservatório de Salto Grande (Americana, SP): caracterização, impactos e propostas de manejo. (E.L.G. Espíndola, M.A. Leite \& C.B. Dornfeld, ed.). Rima, p.155-177.

ARAÚJO, L.M.R. 2009. Estudo das interações fitoplâncton-potozooplâncton no reservatório de Barra Bonita, SP, com ênfase na toxicidade de microcistinas. Dissertação de Mestrado, Universidade Federal de São Carlos, São Carlos.

BAGATINI, I.L. 2006. Avaliação da utilização da comunidade protozooplanctônica (ciliados e sarcodinas) como indicadora da qualidade da água de ambientes da Unidade de Gerenciamento de recursos Hídricos - Mogi-Guaçú-SP. Monografia de Bacharelado em Ciências Biológicas, Universidade Federal de São Carlos, São Carlos.

BARBIERI, S.M. \& GODINHO-ORLANDI, M.J.L. 1989a. Ecological studies on the planktonic protozoa of a eutrophic reservoir (Rio Grande-Brazil). Hydrobiologia 183:1-10. http://dx.doi.org/10.1007/BF00005966

BARBIERI, S.M. \& GODINHO-ORLANDI, M.J.L. 1989b. Planktonic protozoa in a tropical reservoir: temporal variations in abundance and composition. Rev. Hydrobiol. Trop. 22(4):275-285. 
BERNINGER, U.G., FINLAY, B.J. \& KUUPPO, P.L. 1991. Protozoan control of bacterial abundances in freshwater. Limnol. Oceanogr. 36:139-147. http://dx.doi.org/10.4319/lo.1991.36.1.0139

BERNINGER, U.G., WICKHAM, S.A. \& FINLAY, B.J. 1993. Trophic coupling within the microbial food web: a study with fine temporal resolution in a eutrophic freshwater ecosystem. Freshwater Biol. 30:419432. http://dx.doi.org/10.1111/j.1365-2427.1993.tb00825.x

BOSSOLAN, N.R.S. \& GODINHO, M.J.L. 2000. Abundância numérica e composição do protozooplâncton na Lagoa do Infernão, SP. In Estação Ecológica de Jataí.( J.E.S. Santos \& J.S.R. Pires, ed.). RIMA, v.2, 523536p.

BRANDS, S.J. 1989-2005. Systema Naturae 2000. Amsterdam, The Netherlands. http://sn2000.taxonomy.nl/ (último acesso em 14/07/2010).

CAIRNS JUNIOR, J. McCORMICK, P.V. \& NIEDERLEHNER, B.R. 1993. A proposed framework for developing indicators of ecosystem health. Hydrobiologia 263(1):1-44. http://dx.doi.org/10.1007/BF00006084

CASANOVA, S.M.C. 2005. Análise da estrutura da comunidade zooplanctônica na região de desembocadura do Rio Paranapanema na Represa de Jurumirim (SP), com ênfase na dinâmica populacional de Rotifera. Tese de Doutorado em Ciências Biológicas, Universidade Estadual Paulista Júlio de Mesquita Filho, Botucatu.

CHINALIA, F.A. 1996. Caracterização e verificação da aplicabilidade do uso das populações de protozoários para a avaliação da qualidade da água dos rios do Monjolinho e Jacaré-Guaçu, São Carlos-SP. Dissertação de Mestrado, Universidade Federal de São Carlos, São Carlos.

COLE, L. 1994. Catalog of type specimens in the international protozoan type collection. Smithsonian Contributions to Zoology 561:1-28. http:// dx.doi.org/10.5479/si.00810282.561

CORLISS, J.O. 1972. Current status of the international collection of ciliate type-specimens and guidelines for future contributors. Trans. Amer. Microsc. Soc. 91(2):221-235. http://dx.doi.org/10.2307/3225413

CURDS, C.R. 1992. Protozoa and the water industry. Cambridge University Press, New York, 128p.

DURIGAN, J.G., SIPAÚBA-TAVARES, L.H., OLIVEIRA, D.B.S. 1992. Estudo limnológico em tanques de piscicultura. Parte I: variação nictemeral de fatores físicos, químicos e biológicos. Acta Limnol. Brasil. 4:211-223.

ESTEBAN, G.F., FINLAY, B.J., CHARUBHUN, N. \& CHARUBHUN, B. 2001. On the geographic distribution of Loxodes rex (Protozoa, Ciliophora) and other alleged endemic species of ciliates. J. Zool. 255:139-143. http://dx.doi.org/10.1017/S0952836901001200

FINLAY, B.J \& ESTEBAN, G.F. 1998. Freshwater protozoa: biodiversity and ecological function. Biodivers. Conserv. 7:1163-1186. http://dx.doi. org/10.1023/A:1008879616066

FINLAY, B.J. \& FENCHEL, T. 1999. Divergent perspectives on protist species richness. Protist 150:229-233.

FOISSNER, W. 1994. Progress in taxonomy of planktonic freschwater ciliates. Mar. Microb. Food Webs 8 (1-2):9-35.

FOISSNER,W. 1999. Protist diversity: estimates of the near-imponderable. Protist 150:363-368. http://dx.doi.org/10.1016/S1434-4610(99)70037-4

FULONE, L.J., LIMA, A.F., ALVES, G.M., VELHO, L.F.M. \& LANSACTÔHA, F.A. 2005. Composição de amebas testáceas (ProtozoaRhizopoda) de dois córregos do Estado de São Paulo, incluindo novos registros para o Brasil. Acta Sci. Biol. Sci. 27(2):113-118.

GODINHO, M.J.L. \& REGALI-SELEGHIM, M.H. 1999. Diversidade de protozoários de vida livre: protozoa. In Biodiversidade do Estado de São Paulo: síntese do conhecimento ao final do século XX 1. Microrganismos e Vírus (VP. Canhos \& R.F. Vazoller, ed.). FAPESP, São Paulo, p.82-91.

GODINHO, M.J.L. \& REGALI-SELEGHIM, M.H. 2000. Relatório 1 do sub-projeto Protozoa do Projeto "Biodiversidade zooplanctônica e o estado de degradação dos ecossistemas aquáticos continentais do Estado de São Paulo". p.1-10.

GODINHO, M.J.L. \& REGALI-SELEGHIM, M.H. 2001. Relatório 2 do sub-projeto Protozoa do Projeto "Biodiversidade zooplanctônica e o estado de degradação dos ecossistemas aquáticos continentais do Estado de São Paulo". p.40-55.
GODINHO, M.J.L., REGALI-SELEGHIM, M.H. \& KOYAMA, N.S. 2002. Relatório 3 do sub-projeto Protozoa do Projeto "Biodiversidade zooplanctônica e o estado de degradação dos ecossistemas aquáticos continentais do Estado de São Paulo". p.77-108.

GODINHO, M.J.L., REGALI-SELEGHIM, M.H., KOYAMA, N.S, MAI, M.G., BAGATINI, I.L., SPÍNOLA, A.L.G. 2003. Relatório 4 do subprojeto Protozoa do Projeto "Biodiversidade zooplanctônica e o estado de degradação dos ecossistemas aquáticos continentais do Estado de São Paulo". p.7-31.

GONZÁLEZ, J.M. \& SUTTLE, C.A. 1993. Grazing by marine nanoflagellates on viruses and virus-sized particles: ingestion and digestion. Mar. Ecol. Prog. Ser. 94:1-10. http://dx.doi.org/10.3354/meps094001

GOMES, E.A.T. \& GODINHO, M.J.L. 2003. Structure of the protozooplankton community in a tropical shallow and eutrophic lake in Brazil. Acta Oecologica. 24:S153-S161. http://dx.doi.org/10.1016/S1146609X(03)00039-0

GUELLA, G., DINI, F., TOMEI, A. \& PIETRA, F. 1994. Preuplotin, a putative biogenetic precursor of the euplotins, bioactive sesquiterpenoids of the marine ciliated protist Euplotes crassus. J. Chem. Soc.1:161-166.

HISATUGO, K.F. 2009. Avaliação do consumo de bactérias por protozoários in vitro e in situ. Monografia de Bacharelado em Ciências Biológicas, Universidade Federal de São Carlos.

JÜRGENS, K., ARNDT, H. \& ZIMMERMANN,H. 1997. Impact of metazoan and protozoan grazers on bacterial biomass distribution in microcosm experiments. Aquat. Microb. Ecol. 12:131-138. http://dx.doi.org/10.3354/ ame012131

JÜRGENS, K. \& GÜDE, H. 1994. The potential importance of grazingresistant bacteria in planktonic systems. Mar. Ecol. Prog. Ser. 112:169188. http://dx.doi.org/10.3354/meps112169

KOYAMA, N.S. 2001. Avaliação do método da coloração quantitativa com protargol para a análise de ciliados planctônicos. Monografia de Bacharelado em Ciências Biológicas, Universidade Federal de São Carlos.

LAHR, D.J.G. 2006. Taxonomia dos Arcellinida Kent, 1880 (Protista: Ramicristates) do Parque Ecológico do Tietê. Dissertação de Mestrado, Universidade de São Paulo.

LYNN, D.H. 2008. The ciliated Protozoa - characterization, classification, and guide to the literature. 3rd ed. Springer, 605p. PMid: 16325540.

MAI, M.G. 2002. Análise qualitativa e quantitativa dos protozoários na Unidade de Gerenciamento de Recursos Hídricos - Ribeira do Iguape e Litoral Sul do Estado de São Paulo. Monografia de Bacharelado em Ciências Biológicas, Universidade Federal de São Carlos.

MANSANO, A.S. 2008. Caracterização da comunidade protozooplanctônica do Reservatório de Ilha Solteira. Relatório final de Iniciação Científica. FAPESP processo $n^{\circ} 06 / 57209-5,74 \mathrm{p}$.

MANSANO, A.S. 2010. Estudo das comunidades microbianas (bacterioplâncton e protozooplâncton) de uma represa em processo de eutrofização (Represa do Lobo, Itirapina/Brotas-SP). Relatório final de Iniciação Científica. FAPESP processo n ${ }^{\circ}$ 09/00205-6, 76p.

MITCHELL, E.A.D. \& MEISTERFELD, R. 2005. Taxonomic confusion blurs the debate on cosmopolitanism versus local endemism of free living protists. Protist 156:263-267. PMid:15269908. http://dx.doi. org/10.1016/j.protis.2005.07.001

NADAI, R. \& HENRY, R. 2009. Temporary fragmentation of a marginal lake and its effects on zooplankton community structure and organization Braz. J. Biol. 69(3):819-835. http://dx.doi.org/10.1590/S1519 69842009000400009

NALECZ-JAWECKI, G. 2004. Spirotox- Spirostomum ambiguum Acute Toxicity Test- 10 years of experience. Environ. Toxicol.19:359-364. http://dx.doi.org/10.1002/tox.20023

NEUMANN-LEITÃO, S., MATSUMURA-TUNDISI, T. \& CALIJURI, M.C. 1991. Distribuição e aspectos ecológicos do zooplâncton da represa do Lobo (Broa) - São Paulo. In: Anais do Encontro Brasileiro de Plâncton. Recife. 393-414p. 
NOGUEIRA, M.G. 2001. Zooplankton composition, dominance and abundance as indicators of environmental compartmentalization in Jurumirim Reservoir (Paranapanema River), São Paulo, Brazil. Hydrobiologia 455:1-18. http://dx.doi.org/10.1023/A:1011946708757

OLIVEIRA, D.B.S., SIPAÚBA-TAVARES, L.H. \& DURIGAN, J.G. 1992. Estudo limnológico em tanques de piscicultura. Parte II: variação semanal de fatores físicos, químicos e biológicos. Acta Limnol. Brasil. 4:123-137.

PIRLOT, S., VANDERHEYDEN, J., DESCY, J.P. \& SERVAIS, P. 2005. Abundance and biomass of heterotrophic microorganisms in Lake Tanganyika. Freshwater Biol. 50:1219-1232. http://dx.doi.org/10.1111/ j.1365-2427.2005.01395.x

PORTER, K.G., SHERR, E.B., SHERR, B.F., PACE, M. \& SANDERS, R.W. 1985. Protozoa in planktonic food webs. J. Protozool. 32:409-415.

PROWAZEK, S. von. 1910. Contribuição para o conhecimento da fauna de protozoários do Brasil. Mem. Inst. Oswaldo Cruz 2(2):149-158.

REGALI-SELEGHIM, M.H. 1992. Flutuações nas comunidades planctônicas e bentônicas de um ecossistema artificial raso (Represa do MonjolinhoSão Carlos-SP), com ênfase nas populações de protozoários e bactérias. Dissertação de Mestrado, Universidade Federal de São Carlos, São Carlos.

REGALI-SELEGHIM, M.H. 2001. Rede trófica microbiana em um sistema eutrófico raso (Reservatório do Monjolinho-São Carlos-SP) - estrutura e função. Tese de Doutorado, Universidade Federal de São Carlos, São Carlos.

REGALI-SELEGHIM, M.H. 2006. Taxonomia de protozoários. In Taxonomia: microbiana, de procariontes, de fungos, de protozoários e de vírus. (J.L. Azevedo \& R.F. Vazoller, coord.). 50p. Disponível em http//www. cgee.org.br/atividades/redirect.php?idProduto=1752 (último acesso em14/07/2010).

ROLLA, M.E., DABÉS, M.B.G.S., FRANÇA, R.C. \& FERREIRA, E.M.V.M. 1992. Inventário limnológico do Rio Grande na área de influência da futura usina hidrelétrica (UHE) de Igarapava. Acta Limnol. Brasil. 4:139-162.
SANDERS, R.W., PORTER, K.G., BENNET, S.J. \& DeBIASE, A.E. 1989. Seasonal patterns of bacterivory by flagellates, ciliates, rotifers, and cladocerans in freshwater planktonic community. Limnol. Oceanogr. 34:673-687. http://dx.doi.org/10.4319/1o.1989.34.4.0673

SARTORI, L.P., NOGUEIRA, M.G., HENRY, R., MORETTO, E.M. 2009. Zooplankton fluctuations in Jurumirim Reservoir (São Paulo, Brazil): a three-year study. Braz. J. Biol. 69(1):1-18. http://dx.doi.org/10.1590/ S1519-69842009000100002

SHERR, B.F., SHERR E.B., FALLON, R.D. 1987. Use of monodispersed fluorescently labeled bacteria to estimate in situ protozoan bacterivory. Appl. Environ. Microb. (53)5:958-965.

SHERR, E.B. \& SHERR, B.F. 1994. Bacterivory and herbivory: key roles of phagotrophic protists in pelagic food webs. Microb. Ecol. 28:223-235. http://dx.doi.org/10.1007/BF00166812

SIGEE, D.C., GLENN, R., ANDREWS, M.J., BELLINGER, E.G., BUTLER, R.D., EPTON, H.A.S. \& HENDRY, R.D. 1999. Biological control of cyanobacteria: principles and possibilities. Hydrobiologia 395-396:161172. http://dx.doi.org/10.1023/A:1017097502124

SLADEČEK, V. 1969. The indicator value of some free-moving ciliates. Arch. Protistenk. 111:276-278.

SIPAÚBA-TAVARES, L.H., LIGEIRO, S.R. \& DURIGAN, J.G. 1995. Variação de alguns parâmetros limnológicos em um viveiro de piscicultura em função da luz. Acta Limnol. Brasil. 7:138-150.

TRANVIK, L.J., SHERR, E.B., SHERR, B.F. 1993. Uptake and utilization of colloidal DOM by heterotrophic flagellates in seawater. Mar. Ecol. Prog. Ser. 92:301-309. http://dx.doi.org/10.3354/meps092301

TWAGILIMANA, L., BOHATIER, J., GROLIÈRE, C.A., BONNEMOY, F. \& SARGOS, D. 1998. A new low-cost microbiotest with the protozoan Spirostomum teres: culture conditions and assessment of sensitivity of the ciliate to 14 pure chemicals. Ecotoxicol. Environ. Safety 41:231-244. PMCid:1508084. http://dx.doi.org/10.1006/eesa.1998.1698

VICKERMAN, K. 1992. The diversity and ecological significance of Protozoa. Biodivers. Conserv. 1:334-341. http://dx.doi.org/10.1007/BF00693769

Recebido em 14/07/2010

Versão reformulada recebida em 11/10/2010

Publicado em 15/12/2010 